$\pm N=$

Global Journals Inc.

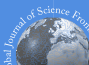

\title{
Effect of Combinations of Mycobacteriophages and Drugs Against Mycobacterium Spp.
}

By Rajitha Satish \& Anita Desouza

Abstract- The emergence of multidrug-resistant tuberculosis (MDR-TB) is a matter of global concern. The use of mycobacteriophages alone or in combination with antibiotics could be used as an alternative approach to treat drug-resistant Mycobacteria. The aim of the study was the evaluation of the effect of an isolated mycobacteriophage in combination with Isoniazid, Rifampicin, Streptomycin, and Ampicillin against Mycobacterium tuberculosis and Mycobacterium smegmatis. Determination of the MIC of the above drugs for each strain was done by the standard tube dilution method. Further, the inhibitory effect of varying drug concentrations in combination with different dilutions of the mycobacteriophage was studied. The growth inhibition pattern for both the organisms was also studied in the presence of different dilutions of mycobacteriophage by turbidometric and resazurin dye reduction method. The killing pattern of drugs, at concentrations below the MIC, when combined with mycobacteriophage, was determined. The phage induced lysis of bacteria assisted in decreasing the inhibitory concentration of the drugs.

Keywords: phage therapy; mycobacteriophages; combination therapies; MDR TB; Mycobacterium tuberculosis; isoniazid, rifampicin, streptomycin, ampicillin, Mycobacterium smegmatis, MIC.

GJSFR-B Classification: FOR Code: 030499

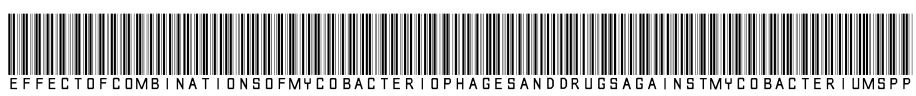

Strictly as per the compliance and regulations of:

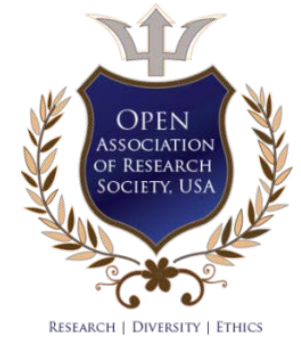

(C) 2019. Rajitha Satish \& Anita Desouza. This is a research/review paper, distributed under the terms of the Creative Commons Attribution-Noncommercial 3.0 Unported License http://creativecommons.org /licenses/by-nc/3.0/), permitting all non commercial use, distribution, and reproduction in any medium, provided the original work is properly cited. 


\title{
Effect of Combinations of Mycobacteriophages and Drugs Against Mycobacterium Spp.
}

\author{
Rajitha Satish ${ }^{\alpha} \&$ Anita Desouza ${ }^{\sigma}$
}

\begin{abstract}
The emergence of multidrug-resistant tuberculosis (MDR-TB) is a matter of global concern. The use of mycobacteriophages alone or in combination with antibiotics could be used as an alternative approach to treat drugresistant Mycobacteria. The aim of the study was the evaluation of the effect of an isolated mycobacteriophage in combination with Isoniazid, Rifampicin, Streptomycin, and Ampicillin against Mycobacterium tuberculosis and Mycobacterium smegmatis. Determination of the MIC of the above drugs for each strain was done by the standard tube dilution method. Further, the inhibitory effect of varying drug concentrations in combination with different dilutions of the mycobacteriophage was studied. The growth inhibition pattern for both the organisms was also studied in the presence of different dilutions of mycobacteriophage by turbidometric and resazurin dye reduction method. The killing pattern of drugs, at concentrations below the MIC, when combined with mycobacteriophage, was determined. The phage induced lysis of bacteria assisted in decreasing the inhibitory concentration of the drugs.
\end{abstract}

Keywords: phage therapy; mycobacteriophages; combination therapies; MDR TB; Mycobacterium tuberculosis; isoniazid, rifampicin, streptomycin, ampicillin, Mycobacterium smegmatis, MIC.

\section{INTRODUCTION}

$\longrightarrow$ rganizations such as the Center for Disease Control (CDC) and the World Health Organization(WHO) have declared that bacterial antibiotic resistance is a threat to global human health. Drug-resistant TB is one of the major causes of the public health crisis. As per the Global WHO report of 2018, in the year 2017 alone, 558,000 cases of Rifampicin-resistant TB (RR-TB) were reported, and of these, $82 \%$ had multidrug-resistant TB (MDR-TB). Three countries across the world account for almost half of the world's cases of MDR/RR-TB: India (24\%), China (13\%), and the Russian Federation (10\%). Treatment for Rifampicin-resistant TB (RR-TB) and multidrug-resistant TB (MDR-TB) is expensive ( $\geq$ US $\$ 1000$ per person). MDR-TB requires that it be treated with second-line drugs for more than 24 months. As these drugs are costly and more toxic, there is a requirement of urgent action for the improvement of the quality of diagnosis and the treatment of drug-resistant TB (Website 1).

TB awareness programs and infection control measures are crucial for preventing transmission of

Author a o: SIES College of Arts, Science and Commerce, Sion West, University of Mumbai. e-mail: rajithasatishb@gmail.com resistant strains. MDR-TB programs that rely on internationally recommended treatment regimens, according to WHO guidelines, must be scaled up and strengthened to prevent further second-line drug resistance and spread of XDR-TB. However, the increase in incidence of XDR-TB is an indirect indicator of the program's failure to adequately diagnose, prevent, and treat MDR-TB. The emergence of XDR-TB in 6 continents, coupled with the increased use of second-line drugs, suggests that urgent measures are needed to improve the rational use of quality-assured second-line drugs, new anti-TB drug regimens and better diagnostic tests for TB and MDR-TB. Such steps are crucial if future generations are to be protected from potentially untreatable TB(Leimane et al., 2005; Shah et al., 2007; Website 2).

The period between 1950 and 1970 was a turning point in the battle against tuberculosis during which the discovery of most of the current antituberculosis drugs occurred, and the therapeutic regimens were introduced that made it possible to cure tuberculosis. However, with the exception of the fluoroquinolones, no new antituberculosis drug has been introduced in the past 45 years. The probability of successful treatment further decreases with the emergence of drug-resistant strains as MDR and XDR tuberculosis generally have a high mortality rate (Caminero et al.,2010).

The global incidence of tuberculosis is increasing, and the existing diagnostic technologies are not adequately accurate. For example, sputum smear microscopy (SSM) is the most widely used diagnostic test for TB as it is a quick test and not difficult to perform, but its sensitivity is low, and it cannot distinguish between viable and dead bacteria. Bacterial culture diagnosis, though time-consuming has better diagnostic accuracy when compared to SSM. Nucleic Acid Amplification Tests (NAATs) have high sensitivity but low specificity (Dinnes, 2007). The tuberculosisspecific ELISPOT assay (T-SPOT.TB) gives an overall measurement of the antigen load on the immune system and thus can reveal the presence of subclinical disease. Since this assay does not depend on the production of a reliable antibody response or the recovery of the pathogen, the technique can be used to detect latent tuberculosis condition(Ahmad, 2010). Due to the rise in prevalence of multidrug-resistant tuberculosis (MDR-TB) and extremely drug-resistant tuberculosis (XDR-TB), 
novel technologies for TB diagnosis, therapy, and prevention are required urgently. These growing concerns have drawn the attention of TB researchers to phages. The biological characteristics of phages enable them to be advantageous in treating drug-resistant bacterial infections (Guo and Zhi,2012).

On September 21, 2016, the United Nations General Assembly convened to discuss the problem of antibiotic resistance and deemed it "the greatest and most urgent global risk". One of the popular suggestions for an alternative strategy for prophylaxis and control of bacterial infections was phage therapy. Phage therapy, which implies the use of viruses (phages) to treat bacterial infections, has been around for almost a century. The universal decline in the effectiveness of antibiotics has generated renewed interest in phage therapy, which has several advantages over antibiotics such as host specificity, selfamplification, biofilm degradation, and low toxicity to humans (Lin et al., 2017).

Though phages have been extensively used therapeutically in the former Soviet Union countries, they have yet to find widespread use in other parts of the world. Phage preparations for use against E.coli and Listeria meat contamination have received approvals and trials are in progress for control of several infections involving skin afflictions and burns (Hatfull, 2014). Mycobacteriophages are viruses that infect mycobacterial hosts, such as Mycobacterium tuberculosis and Mycobacterium smegmatis (Hatfull, 2012).

A number of mycobacteriophages from different environmental samples and their sequenced genomes have been reported by the Phage Hunters Integrating Research and Education (PHIRE) program at the University of Pittsburgh, and the Science Education Alliance Phage Hunters Advancing Genomics and Evolutionary Sciences (SEA-PHAGES) program by Professor Graham Hatfull and his coworkers (Hatfull,2014). As mycobacteriophages infect Mycobacteria, resulting in their lysis and death, the possibility of using them as therapeutic agents against the deadly mycobacterial disease, tuberculosis is of great interest. Of the many mycobacteriophages isolated, the lytic phage TM4 and the lysogenic phage L5 have been extensively studied (Samaddar et al., 2016).

Mycobacteriophages display a remarkable genetic diversity. Till date, 10552 mycobacteriophages have been identified, of which 1795 have been sequenced (Website 3 ). The sequenced mycobacteriophage genomes get grouped into clusters and subclusters based on their sequence identity. About 30 distinct types (called clusters or singletons if they have no similarities) have been identified. The clusters that span sufficient diversity warrant further division into subclusters. Host range analysis shows that phages in
Cluster K, and certain subclusters(A2 and A3) of Cluster A, efficiently infect $M$. tuberculosis (Hatfull,2014).

In the year 2019, Nature Medicine reported the case of a 15-year-old cystic fibrosis patient with a Mycobacterium abscessus infection; treated with a cocktail of three mycobacteriophages. Hatfull and his team searched through a phage library of over 10,000 different phages to find the phages that would most effectively kill the mycobacterial strain in the abscess. One of the three phages was lysogenic and was converted by genome engineering to a lytic phage. The phages were delivered intravenously. The treatment was well tolerated and was successful in bringing about sternal wound closure, improved liver function, and substantial resolution of the infected skin nodules (Dedrick et al., 2019).

D29 mycobacteriophage was used first for TB diagnosis, and later it showed potential as a therapeutic agent against TB. It was effective in treating guinea pigs infected with both drug-sensitive and drug-resistant $M$. tuberculosis strains (Li et al., 2009). TM4 has been reported to kill fast-growing Mycobacteria such as M.smegmatis as well as the slow-growing M.tuberculosis H37Rv and M.ulcerans(Pope et al.,2011).Researchers have predicted that as TM4 has the most highly expressed genome and the greatest ability to kill mycobacteria in vivo, it might be the best choice for phage therapy against TB. Among the Cluster $\mathrm{K}$ phages, extensive research has been done to date, only with TM4, and it is anticipated that in the future more Cluster $\mathrm{K}$ phages will be developed for therapeutic use. For successful phage therapy, the challenge is to create an ideal transport vehicle that would allow the mycobacteriophage to be administered into the human body (Abedon et al., 2011). Although TM4 is being considered for use in TB therapy, additional novel safe phages that can treat TB effectively need to be obtained or constructed through genetic recombination. The aim would be to establish a repository of therapeutic phages and thereby provide more choices for combination therapy strategies to treat TB. In recent years, phage therapy has gained significance in light of the increasingly alarming situation of drug-resistant TB around the world(Guo and Zhi, 2012).

The efficiency with which the bacteriophages can reduce the bacterial load will depend on the number of phages present, the adsorption efficiency of the phage, its life cycle, the length of the latent phase, the burst size and the growth rate of the host. In order to put mycobacteriophages to therapeutic use, it is necessary to study the mechanism by which they bring about a reduction in the bacterial population and to determine a quantitative relationship between phage growth and decrease in bacterial numbers(Samaddar et al., 2016).

In the present study, we have attempted to study the relationship between phage and bacterial growth in order to determine the effect of the number of 
mycobacteriophages on host inactivation. We also studied the combined effect of various antibiotics and mycobacteriophages which may serve as an alternative treatment for tuberculosis. We attempted to determine whether the phage induced lysis of Mycobacterium, would assist in decreasing, the MIC of the anti TB drug. The understanding of these mechanisms will enable the development of new strategies to combat tuberculosis.

The aim of the study was to determine the antibacterial effect of mycobacteriophage individually or in combination with varying concentrations of antibiotics so that they can eventually be used as antimycobacterial therapeutic agents either alone or in combination with antibiotics

\section{il. Materials and Methods}

\section{a) Cultivation of Mycobacterium spp.}

Mycobacterium smegmatis MTCC 994 and Mycobacterium tuberculosis MTCC 300(IMTECH, Chandigarh) both non-virulent mycobacterial strains were used for the study of the mycobacteriophages previously isolated (Satish and Desouza, 2018). The strains were cultivated in Nutrient broth at $37^{\circ} \mathrm{C}$ for 48 hrs.

\section{b) Phage isolation}

In a previous study, ten mycobacteriophages were obtained from soil and sewage samples using Mycobacterium smegmatis MTCC 994 as host. Of the ten phages obtained, three were found to infect four different species of Mycobacterium, namely M. fortuitum subsp. fortuitum MTCC 993, Mycobacterium kansasii MTCC 3058, Mycobacterium avium subsp. avium MTCC 1723, and M. tuberculosis MTCC 300, besides the host M. smegmatis (Satish and Desouza, 2018). Characterization of the growth parameters of one of the mycobacteriophages which exhibited host diversity was done in an earlier study (Satish and Desouza, 2019). This mycobacteriophage was chosen in the present study to determine the combined effect of phage and antibiotics against $M$. tuberculosis and $M$. smegmatis.

\section{c) Antimicrobial agents}

Four anti-tuberculosis drugs were used in the present study. Isoniazid, Rifampicin, and Ampicillin were obtained from Hi-Media Laboratories, and Streptomycin was obtained from Ambistryn S.

\section{d) Determination of Minimum Inhibitory Concentration of the drugs}

The MIC of Isoniazid, Rifampicin, Streptomycin, and Ampicillin was determined for both the Mycobacterial strains by the standard broth dilution method. Various drug concentrations in the range, as listed in Table 1, were prepared in $5 \mathrm{ml}$ of Mueller Hinton medium and inoculated with $100 \mu \mathrm{l}$ of $48 \mathrm{hr}$ old inoculum having a density of $0.1 \mathrm{OD}_{530}$. The tubes were incubated at $37^{\circ} \mathrm{C}$ for $24-48 \mathrm{hrs}$. The MIC was determined as the lowest drug concentration at which there was no visible bacterial growth. Each drug concentration was tested in triplicate.

Table 1: Drug range to determine MIC

\begin{tabular}{|l|l|l|}
\hline \multicolumn{1}{|c|}{ Organism } & $\begin{array}{c}\text { Mycobacterium } \\
\text { tuberculosis } \\
\text { MTCC 300 }\end{array}$ & $\begin{array}{c}\text { Mycobacterium } \\
\text { smegmatis } \\
\text { MTCC 994 }\end{array}$ \\
\hline Isoniazid & $1.0-10.0 \mathrm{mg} / \mathrm{ml}$ & $0.25-1.5 \mathrm{mg} / \mathrm{ml}$ \\
\hline Rifampicin & $0.5-10.0 \mu \mathrm{g} / \mathrm{ml}$ & $50.0-500.0 \mu \mathrm{g} / \mathrm{ml}$ \\
\hline Streptomycin & $1.0-10.0 \mu \mathrm{g} / \mathrm{ml}$ & $0.5-5.0 \mu \mathrm{g} / \mathrm{ml}$ \\
\hline Ampicillin & $50.0-500.0 \mu \mathrm{g} / \mathrm{ml}$ & $0.1-1.0 \mathrm{mg} / \mathrm{ml}$ \\
\hline
\end{tabular}

e) Inhibitory effect of a combination of drug and mycobacteriophage

The assay was performed in a 96well microtiter plate. The inoculum used was a saline suspension of 48 hr old culture of Mycobacterium tuberculosis MTCC 300 or Mycobacterium smegmatis MTCC $994\left(\mathrm{OD}_{530}-0.1\right)$. To determine the inhibitory effect of a combination of drug and mycobacteriophage; the drug concentrations chosen were the MIC value itself, and one concentration above and below the MIC for each of the drugs.

Into the wells in Row A was added $250 \mu$ l of drug of the given concentration prepared in $\mathrm{MH}$ broth and $50 \mu \mathrm{l}$ of culture Mycobacterium tuberculosis MTCC 300. The drug concentrations ranged as follows - Isoniazid $1.0-5.0 \mathrm{mg} / \mathrm{ml}$, Rifampicin - 0.25-3.0 $\mu \mathrm{g} / \mathrm{ml}$, Streptomycin

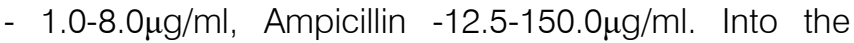
wells in Row B was added $125 \mu$ of each drug concentration prepared in $\mathrm{MH}$ medium; $125 \mu \mathrm{l}$ of mycobacteriophage $\left(10^{6} \mathrm{pfu} / \mathrm{ml}\right)$ and $50 \mu \mathrm{l}$ of culture Mycobacterium tuberculosis MTCC 300. The final drug concentration achieved in Row B was the same as in Row A. Row C consisted of controls. The positive control consisted of $250 \mu \mathrm{l}$ of sterile $\mathrm{MH}$ broth and $50 \mu \mathrm{l}$ of culture Mycobacterium tuberculosis MTCC 300. The medium control consisted of $300 \mu \mathrm{l}$ of sterile $\mathrm{MH}$ broth. The phage control consisted of $125 \mu \mathrm{l}$ of sterile $\mathrm{MH}$ broth, $125 \mu \mathrm{l}$ of mycobacteriophage $\left(10^{6} \mathrm{pfu} / \mathrm{ml}\right)$, and $50 \mu \mathrm{l}$ of culture Mycobacterium tuberculosis MTCC 300. The plates were incubated at $37^{\circ} \mathrm{C}$ for $24 \mathrm{hrs}$, after which $30 \mu \mathrm{l}$ of resazurin $(0.015 \%)$ were added to all the wells, further incubated at $37^{\circ} \mathrm{C}$ for $2-4 \mathrm{hrs}$ and observed for color change (blue to pink). The assay was performed similarly for Mycobacterium smegmatis MTCC 994. The drug concentrations used were as follows -Isoniazid $0.25-1.5 \mathrm{mg} / \mathrm{ml}$, Rifampicin - $50.0 \quad-500.0 \mu \mathrm{g} / \mathrm{ml}$,

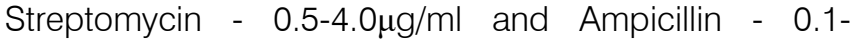
$1.0 \mathrm{mg} / \mathrm{ml}$

f) Synergistic Inhibitory effect of drug and Mycobacteriophage

i. Assay using resazurin dye reduction

The assay was performed in a 96 well microtiter plate. The drug ranges used were as follows - Isoniazid - $\quad 1.0-5.0 \mathrm{mg} / \mathrm{ml}$, Rifampicin - $0.25-3.0 \mu \mathrm{g} / \mathrm{ml}$, 


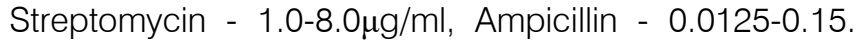
The additions in the five rows were as follows: Row $\mathrm{A}$ In the first five wells $-125 \mu$ l of the various concentrations of each drug prepared in sterile $\mathrm{MH}$ broth, $125 \mu$ l of mycobacteriophage $\left(10^{6} \mathrm{pfu} / \mathrm{ml}\right)$ and $50 \mu \mathrm{l}$ of culture suspension of Mycobacterium tuberculosis MTCC $300\left(\mathrm{OD}_{530}-0.1\right)$. Rows $\mathrm{B}, \mathrm{C}$, and $\mathrm{D}$ had the same drug concentrations as Row $\mathrm{A}$, while the phage added had a count of $10^{5} \mathrm{pfu} / \mathrm{ml}, 10^{4} \mathrm{pfu} / \mathrm{ml}, 10^{3} \mathrm{pfu} / \mathrm{ml}$, respectively. Row $E$ consisted of $250 \mu$ l of the various concentrations of each drug prepared in sterile $\mathrm{MH}$ broth and $50 \mu \mathrm{l}$ of culture suspension of Mycobacterium tuberculosis MTCC 300. In Row A, the last two wells were medium controls consisting of the only $300 \mu$ l of sterile $\mathrm{MH}$ broth. In Row B, the last two wells were phage controls consisting of $125 \mu \mathrm{l}$ of sterile $\mathrm{MH}$ broth, $125 \mu \mathrm{l}$ of mycobacteriophage $\left(10^{6} \mathrm{pfu} / \mathrm{ml}\right)$, and $50 \mu \mathrm{l}$ of culture suspension of Mycobacterium tuberculosis MTCC 300. In Row C, the last two wells were positive controls consisting of $250 \mu \mathrm{l}$ of sterile $\mathrm{MH}$ broth and $50 \mu \mathrm{l}$ of culture Mycobacterium tuberculosis MTCC 300. The plates were incubated at $37^{\circ} \mathrm{C}$ for $24 \mathrm{hrs} .30 \mu \mathrm{l}$ of resazurin $(0.015 \%)$ were then added to all the wells, further incubated at $37^{\circ} \mathrm{C}$ for $2-4 \mathrm{hrs}$ and observed for color change. With Mycobacterium smegmatis MTCC 994 the experiment was performed in a similar manner. The drug concentrations range used for Mycobacterium smegmatis MTCC 994 were as follows:Isoniazid -0.25$1.5 \mathrm{mg} / \mathrm{ml}$, Rifampicin-50.0-300.0 $\mathrm{gg} / \mathrm{ml}$, Streptomycin$0.5-4.0 \mu \mathrm{g} / \mathrm{ml}$, Ampicillin- 0.1-1.0 mg/ml

ii. Mycobacterial Growth Pattern in the presence of mycobacteriophage and drug

The experimental set up was the same as in the previous experiment. The growth was determined by measuring turbidity and not by resazurin reduction. After adding the culture to the wells, the plates were incubated at $37^{\circ} \mathrm{C}$ for $18 \mathrm{hrs}$. Culture turbidity was determined at intervals of 3 hours by measurement of the absorbance of each well at 530nm with a microplate reader with moderate shaking at intervals of $30 \mathrm{~min}$. A graph of Time (hrs) vs. Absorbance ${ }_{530}$ was plotted to determine changes in growth pattern.

g) Mycobacterial Growth Pattern in the presence and absence of mycobacteriophage

The assay was performed in a 96well microtiter plate. For the control set, $50 \mu$ l of saline suspension $\left(\mathrm{OD}_{530^{-}} \quad 0.1\right)$ of the host culture (Mycobacterium tuberculosis MTCC 300 or Mycobacterium smegmatis MTCC 994) was added to wells containing $250 \mu$ of sterile Nutrient broth. For the test set $50 \mu \mathrm{l}$ of saline suspension $\left(\mathrm{OD}_{530}-0.1\right)$ of the host culture (Mycobacterium tuberculosis MTCC 300 or Mycobacterium smegmatis MTCC 994) was added to wells containing $125 \mu \mathrm{l}$ of sterile Nutrient Broth and $125 \mu \mathrm{l}$ of phage suspension of two different counts $\left(10^{6} \mathrm{pfu} / \mathrm{ml}\right.$, $10^{5} \mathrm{pfu} / \mathrm{ml}$ ) respectively. The plates were then incubated at $37^{\circ} \mathrm{C}$ for $24 \mathrm{hrs}$. Culture turbidity was determined at an interval of 3 hours for a period of 24 hours by measurement of the absorbance of each well at $530 \mathrm{~nm}$ with a microplate reader with moderate shaking at intervals of $30 \mathrm{~min}$.

\section{Results}

The MIC was determined by the tube dilution method for four antituberculosis drugs - Isoniazid, Rifampicin, Streptomycin, and Ampicillin against two organisms-Mycobacterium tuberculosis MTCC 300 and Mycobacterium smegmatis MTCC 994.The results are presented in Table 2.

Table 2: MIC of antituberculosis drugs

\begin{tabular}{|c|c|c|}
\hline Organism & $\begin{array}{c}\text { Mycobacterium } \\
\text { tuberculosis } \\
\text { MTCC 300 }\end{array}$ & $\begin{array}{c}\text { Mycobacterium } \\
\text { smegmatis } \\
\text { MTCC 994 }\end{array}$ \\
\hline Drugs & MIC & MIC \\
\hline Isoniazid & $5.0 \mathrm{mg} / \mathrm{ml}$ & $1.5 \mathrm{mg} / \mathrm{ml}$ \\
\hline Rifampicin & $2.0 \mu \mathrm{m} / \mathrm{ml}$ & $200.0 \mu \mathrm{g} / \mathrm{ml}$ \\
\hline Streptomycin & $4.0 \mu \mathrm{gl}$ & $2.0 \mu \mathrm{ml} / \mathrm{ml}$ \\
\hline Ampicillin & $0.1 \mathrm{mg} / \mathrm{ml}$ & $1.0 \mathrm{mg} / \mathrm{ml}$ \\
\hline
\end{tabular}

The experiment for the inhibitory effect of a combination of drug and mycobacteriophage was performed using different concentrations of the drugs and mycobacteriophage in microtiter plates. Resazurin was used to determine the presence of viable cells. It is a redox indicator dye which is blue in its oxidized state and gets reduced to pink resorufin by metabolically active cells. There is a direct correlation between the reduction of resazurin in a growth medium and the proliferation of live organisms. The results interpretation was as follows - wells with no color change (blue resazurin) were reported as no growth whereas wells, where resazurin had turned pink were reported as growth.

Figures 1,2,3 and 4 show the synergistic inhibitory action of mycobacteriophages with Isoniazid, Rifampicin, Streptomycin, and Ampicillin respectively against Mycobacterium tuberculosis MTCC 300. In all the four figures, Row A indicates the MIC of the drug against Mycobacterium tuberculosis MTCC 300. The MIC so determined is as follows - Isoniazid $-5.0 \mathrm{mg} / \mathrm{ml}$

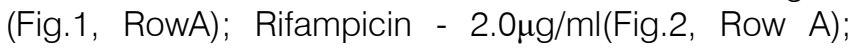

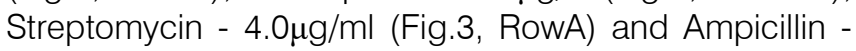
$0.1 \mathrm{mg} / \mathrm{ml}$ (Fig.4, RowA). Row B, in all the four figures, contained the respective drug concentrations combined with mycobacteriophages. No growth was seen in all the wells in Row B, including the well containing the lowest concentration of the drugs. Row $\mathrm{C}$, in all the figures, contained controls.

Figures 5, 6, 7, and 8 similarly show the synergistic inhibitory action of mycobacteriophages with Isoniazid, Rifampicin, Streptomycin, and Ampicillin respectively against Mycobacterium smegmatis MTCC 
994. The MIC of the drugs against Mycobacterium smegmatis MTCC 994determined by the results in Rows $A$ is as follows - Isoniazid- $1.5 \mathrm{mg} / \mathrm{ml}$ (Fig.5, Row A); Rifampicin-200.0 $\mu \mathrm{g} / \mathrm{ml}$ (Fig.6, Row A); Streptomycin$2.0 \mu \mathrm{g} / \mathrm{ml}$ (Fig.7, Row A) and Ampicillin $-1.0 \mathrm{mg} / \mathrm{ml}$ (Fig.8, Row A). Row $B$, in all the four figures, contained the respective drug concentrations combined with mycobacteriophages. Similar to the experiment with Mycobacterium tuberculosis MTCC 300 , no growth was seen in all the wells in Row $B$, including the well containing the lowest concentration of the drugs. Row $\mathrm{C}$, in all the figures, contained controls.

Figures 9, 10, 11, and 12 represent the synergistic inhibitory action of various mycobacteriophage dilutions with varying concentrations of Isoniazid, Rifampicin, Streptomycin, and Ampicillin respectively against Mycobacterium tuberculosis MTCC 300. Row E, inall the four figures, contains only drug and thus indicates the minimum inhibitory concentration of the given drug. The MIC obtained are as similar to the previous experiment namely Isoniazid-5.0mg/ml (Fig.9, Row E); Rifampicin $2.0 \mu \mathrm{g} / \mathrm{ml}$ (Fig.10, Row E); Streptomycin - $4.0 \mu \mathrm{g} / \mathrm{ml}$ (Fig.11, Row E) and Ampicillin $-0.1 \mathrm{mg} / \mathrm{ml}$ (Fig.12, Row $E)$. In all the four figures, Row $A, B, C$, and $D$ consist of combinations of drugs with different mycobacteriophage dilution. In all the four sets, Row $\mathrm{A}$ and $\mathrm{B}$ that contained mycobacteriophages at $10^{6} \mathrm{pfu} / \mathrm{ml}$ and $10^{5} \mathrm{pfu} / \mathrm{ml}$ respectively, there was no visible growth even in the wells containing the least concentration of the drugs. However, in Row C and D that contained mycobacteriophages at $10^{4} \mathrm{pfu} / \mathrm{ml}$ and $10^{3} \mathrm{pfu} / \mathrm{ml}$ respectively, there was visible growth in all the wells having drug concentrations below the MIC.

Results of the similar experiments with Mycobacterium smegmatis MTCC 994 are shown in figures $13,14,15$, and 16. The MIC determined from the results in Row $E$ is as follows - Isoniazid $1.5 \mathrm{mg} / \mathrm{ml}$ (Fig.13,Row E); Rifampicin - 200.0 $\mu \mathrm{g} / \mathrm{ml}$

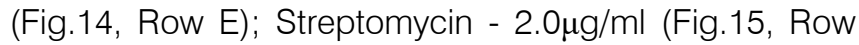
E) and Ampicillin - 1.0mg/ml(Fig.16, Row E). Similar to the results obtained for Mycobacterium tuberculosis
MTCC 300, there was no visible growth in rows $A$ and $B$ where the mycobacteriophage density was $10^{6} \mathrm{pfu} / \mathrm{ml}$ and $10^{5} \mathrm{pfu} / \mathrm{ml}$ respectively; while in rows $C$ and $D$ that contained mycobacteriophages at $10^{4} \mathrm{pfu} / \mathrm{ml}$ and $10^{3} \mathrm{pfu} / \mathrm{ml}$ respectively, there was visible growth in all the wells that had drug concentrations below the MIC. Thus the lower concentration of mycobacteriophage i.e $10^{4} \mathrm{pfu} / \mathrm{ml}$ and $10^{3} \mathrm{pfu} / \mathrm{ml}$ were not effective in killing the organisms whereas higher mycobacteriophage concentration of $10^{6} \mathrm{pfu} / \mathrm{ml}$ and $10^{5} \mathrm{pfu} / \mathrm{ml}$ were able to inhibit microbial growth. It is evident that $\mathrm{MOI}$ plays a role in the efficiency of the lytic activity of the phage. Thus a minimum phage count is required to be effective in inhibiting the growth of Mycobacterium.

Growth patterns in the presence of drugs Isoniazid, Rifampicin, Streptomycin, and Ampicillin at concentrations below the MIC of the drugs and in combination with mycobacteriophage count of $10^{6} \mathrm{pfu} / \mathrm{ml}$ for $18 \mathrm{hrs}$ are presented in figures $17,18,19$ and 20 for $M$. tuberculosis and in figures 21, 22, 23 and 24 for $M$. smegmatis. It was observed that in all the cases, the phages were effective in killing the organisms within 3hours while in the presence of drugs alone, the growth rate was reduced to some extent, but total inhibition was not seen.

The growth patterns of Mycobacterium tuberculosis MTCC 300 and Mycobacterium smegmatis MTCC 994 were studied in the presence and absence of phage counts of $10^{6} \mathrm{pfu} / \mathrm{ml}$ and $10^{5} \mathrm{pfu} / \mathrm{ml}$. As seen in figures 25 and 26 the mycobacteriophages having counts of $10^{6} \mathrm{pfu} / \mathrm{ml}$ and $10^{5} \mathrm{pfu} / \mathrm{ml}$ were able to suppress bacterial growth of both organisms over the 24 hour period of the study.

\section{Discussions}

Mycobacteriophages (106 $\mathrm{pu} / \mathrm{ml}$ and $\left.10^{5} \mathrm{pfu} / \mathrm{ml}\right)$ were efficient in killing both Mycobacterium tuberculosis MTCC 300 and Mycobacterium smegmatis MTCC 994. In the presence of phage, the growth of the organisms was inhibited even at the least concentration of the drug tested (Table 3).

Table 3: Inhibitory concentrations of the drugs in presence and absence of phage

\begin{tabular}{|c|c|c|c|c|}
\hline Organism & \multicolumn{2}{|c|}{ Mycobacterium tuberculosis MTCC 300 } & \multicolumn{2}{|c|}{ Mycobacterium smegmatis MTCC 994 } \\
\hline Drugs & $\begin{array}{c}\text { Minimum } \\
\text { Inhibitory } \\
\text { Concentration }\end{array}$ & $\begin{array}{c}\text { Least drug concentration } \\
\text { inhibiting growth in the } \\
\text { presence of phage }\end{array}$ & $\begin{array}{c}\text { Minimum Inhibitory } \\
\text { Concentration }\end{array}$ & $\begin{array}{c}\text { Least drug concentration } \\
\text { inhibiting growth in the } \\
\text { presence of phage }\end{array}$ \\
\hline Isoniazid & $5.0 \mathrm{mg} / \mathrm{ml}$ & $1.0 \mathrm{mg} / \mathrm{ml}$ & $1.5 \mathrm{mg} / \mathrm{ml}$ & $0.25 \mathrm{mg} / \mathrm{ml}$ \\
\hline Rifampicin, & $2.0 \mu \mathrm{m} / \mathrm{ml}$ & $0.25 \mu \mathrm{g} / \mathrm{ml}$ & $200.0 \mu \mathrm{g} / \mathrm{ml}$ & $50.0 \mu \mathrm{gl} / \mathrm{ml}$ \\
\hline Streptomycin & $4.0 \mu \mathrm{g} / \mathrm{ml}$ & $1.0 \mu \mathrm{gl} / \mathrm{ml}$ & $2.0 \mu \mathrm{gl} / \mathrm{ml}$ & $0.5 \mu \mathrm{gl} / \mathrm{ml}$ \\
\hline Ampicillin & $0.1 \mathrm{mg} / \mathrm{ml}$ & $0.0125 \mathrm{mg} / \mathrm{ml}$ & $1.0 \mathrm{mg} / \mathrm{ml}$ & $0.1 \mathrm{mg} / \mathrm{ml}$ \\
\hline
\end{tabular}

Bacteria on which phage has been adsorbed are ultimately destined to be lysed after about 60 min of infection, which is the latent period. In a continuous infection model, phage adsorption will take place continuously, accompanied by lysis. Simple mathematical modeling predicts that within $100 \mathrm{~min}$, the number of susceptible bacteria should go down by at least 100 fold at an $\mathrm{MOI}$ of 0.1 . Such a hundred fold reduction in cell counts should result in substantial changes in optical density (Samaddar et al.,2016). A 
previous study (Pereira et al., 1983) reported the inability of phage D29 to completely lyse $M$. smegmatis host cells where it was shown that the optical density decreased to about $50 \%$ of the initial level in 2 hrs. However, they found that a mutant of D29 was able to achieve a much higher level of lysis (Pereira et al., 1983).In the present study, complete lysis of bacteria was observed at a higher mycobacteriophage concentration of $10^{6} \mathrm{pfu} / \mathrm{ml}$ and $10^{5} \mathrm{pfu} / \mathrm{ml}$. This mycobacteriophage induced lysis of bacteria helped to reduce the MIC of the drugs against the organism. However, at lower mycobacteriophage concentrations, the extent of lysis decreased significantly.

Based on the investigations performed in the study by Samaddar et al., (2016), a model was proposed to explain lysis of bacteria in the presence of phage. As per this model, in the presence of phage, a fraction of the cells are lysed, resulting in death by lysis $(\mathrm{DL})$, whereas cells present in the remaining fraction that do not come in contact with the phage undergo death through secondary mechanisms, termed death without lysis (DWL). The phenomenon of DWL probably involves superoxide radicals. However, DWL also can happen due to other reasons, such as the induction of programmed cell death (PCD) through the mediation of toxin-antitoxin (TA) systems, as observed in the case of E. coli cells infected with phage P4. The cycle of infection, phage release, and cell death through secondary mechanisms continue to be repeated, resulting in the lowering of viable cell counts by several orders of magnitude. However, further investigations need to be undertaken to deduce the pathways, involved in the generation of these reactive species.

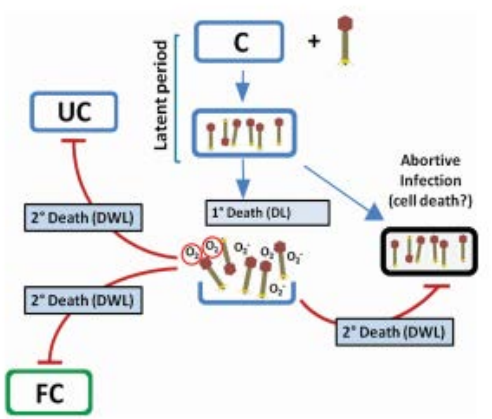

Fig. 1: Model to describe phage-induced killing of host cells (Samaddar et al, 2016)

\section{Conclusion}

The isolated mycobacteriophage at a concentration of $10^{5} \mathrm{pfu} / \mathrm{ml}$ and above was effective in killing both the organisms Mycobacterium tuberculosis MTCC 300and Mycobacterium smegmatis MTCC 994 even in the absence of drugs. This was observed by the resazurin dye reduction test. It was also confirmed by determining growth patterns by measuring turbidity. The mycobacteriophage was effective in inhibiting the growth of both the Mycobacterial spp. upto 24 hours of study. It appears that the mycobacteriophage used in this study has the potential for therapy against Mycobacterium spp. The phage was highly effective in reducing the MIC of the drugs against the organisms. Therefore it would be useful in reducing the concentration of drugs to be consumed and in decreasing the toxic effects of long term drug usage.

To use bacteriophages as pharmaceuticals in the future, it is necessary to obtain a quantitative and mechanistic insight into how they bring about a reduction in the bacterial population. Samaddar et al., (2016) have reported that bacteriophages can reduce bacterial counts and the efficiency with which the bacterial loads are reduced will depend on the number of phages present, their adsorption efficiency, the phagelife cycle, length of the latent period and the growth rate of the host.

Even though it is known that phages being host specific are nonpathogenic to humans, it is important to ensure that the phages are not capable of gene transduction and that they do not carry antibiotic resistance genes (Sulakvelidze et al., 2001). Thus, it is necessary to make a systematic toxicological analysis along with the studies at the molecular level on the candidate phage before large scale clinical trials. Also, the phage should be of low immunogenicity, as exogenous microorganisms may trigger an immune response. A previous study showed that phages were cleared by the reticuloendothelial system when they entered the human body through the circulatory system, resulting in low phage titres at the site of infection; that were not sufficiently high to have a maximal therapeutic effect. Therefore, novel phages with low immunogenicity should be obtained by screening phage mutants, or by genetic reconstruction, or by coating them with biocompatible materials, to escape removal by the immune system(Guo and Zhi, 2012; Merril et al., 1996; Vitielloet al.,2005).

One of the most important problems in the realization of phage therapy is the emergence of resistant bacterial strains. The adsorption of phage to bacterial cells is dependent on the presence of specific receptors on the cell wall. Tanji (2004), in his study introduced a rational procedure for selecting an effective phage cocktail for controlling E.coli. The use of a cocktail of two phages delayed the emergence of phage resistant $E$. coli cells. Based on the results obtained in this study, a cocktail consisting of more than two phages that bind to different cell receptors will help delay and even suppress the emergence of phage resistant bacteria (Tanji, 2004). This is similar to the concept of combination antibiotic therapy. Researchers have found that phage mixtures can prevent resistant bacteria from arising during the therapeutic use of phage, and the time before emergence of resistant 
bacteria could be prolonged through optimization of the phage cocktail (Tanji,2005). The question that needs to be addressed is whether administration of large doses of phage will cause any side effects or even be fatal. However, the advantage of phage therapy is that since phages are composed of protein and DNA, their toxicity is low in a different cell system(Merril et al.,1996). In addition, when phage particles get degraded, toxic metabolites are not produced, as would happen with the metabolism of antibiotics. Therefore, high dose treatment will not result in toxicity; except may be a mild allergic reaction to the phage capsid protein, though such reactions are likely to be uncommon (Abedonand Thomas-Abedon,2010).

There is a great need to explore and focus on novel treatments like phage therapy due to the fast advent of MDR TB. Phage therapy using reported or newly isolated mycobacteriophages can be considered as an adjunct to antibiotic treatment alone or in combination against drug-resistant TB. The intracellular nature of mycobacterial infection complicates the phage delivery method, which can be overcome either by using nonpathogenic Mycobacterium infected with the mycobacteriophage or employing a delivery system such as liposome-mediated phage delivery (Gondiland Chhibber, 2018).

Delivery of phages to the lungs should be relatively simple, although there is considerable doubt as to whether they would effectively reach their bacterial hosts, which may be intracellular and within granulomas. A suggestion for addressing this issue was proposed by Broxmeyar et al.,(2002), who studied the use of infected, non-virulent, surrogate mycobacterial cells for the delivery of phages.

The ability of bacteriophages to act as bactericidal agents has prompted researchers to consider them as an alternative to antibiotics as they could be used directly to destroy the pathogens. Many of the phage-encoded products, such as lysins, are highly toxic to bacteria; therefore, instead of using the phages directly, their products could also be used. Finally, it is important to note that phages have the ability to inhibit the metabolism of their hosts (host inactivation); hence, by understanding how they perform this act, it may be possible to develop new strategies that do not necessarily use the phage directly for intervention against bacterial diseases (Matsuzaki et al., 2005; Sammadar et al.,2016).

The rapid development of proteomics, genomics, bioinformatics, and other disciplines strongly supports basic phage research. Therefore, it is clear that while the study of phage therapy for treating TB is still in the in-vitro and animal experimentation stages; further research is necessary so that a novel effective method for the treatment of drug-resistant TB will be available in the future, which will potentially shorten the duration of the chemotherapy treatment.

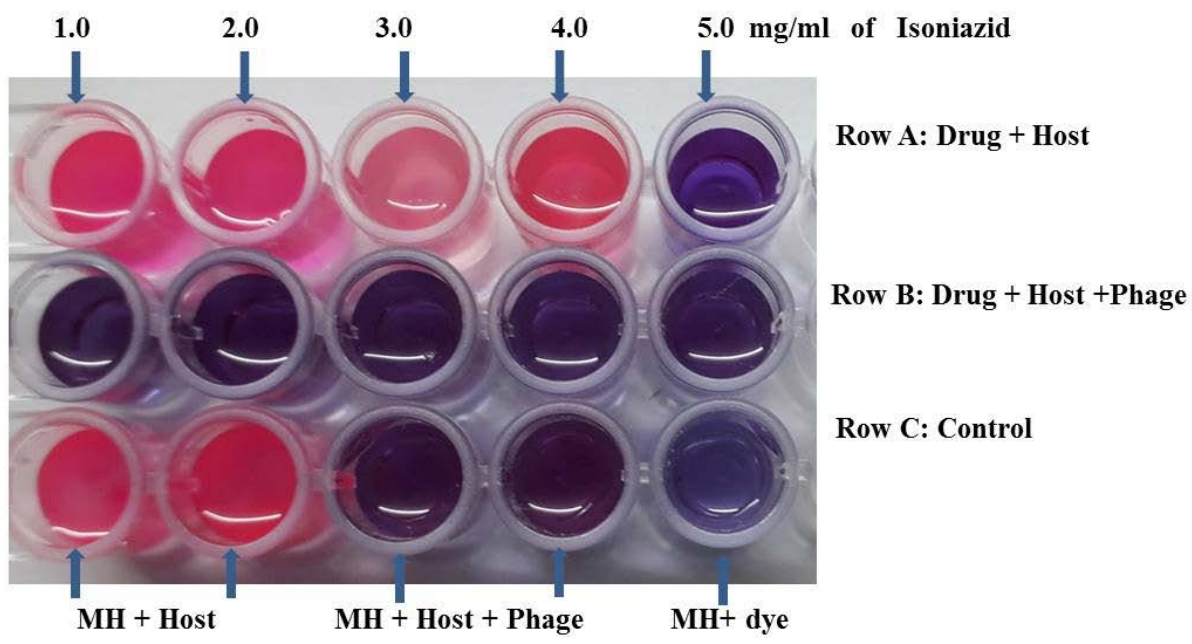

Figure 1: Synergistic action of mycobacteriophage and isoniazid on Mycobacterium tuberculosis MTCC 300 


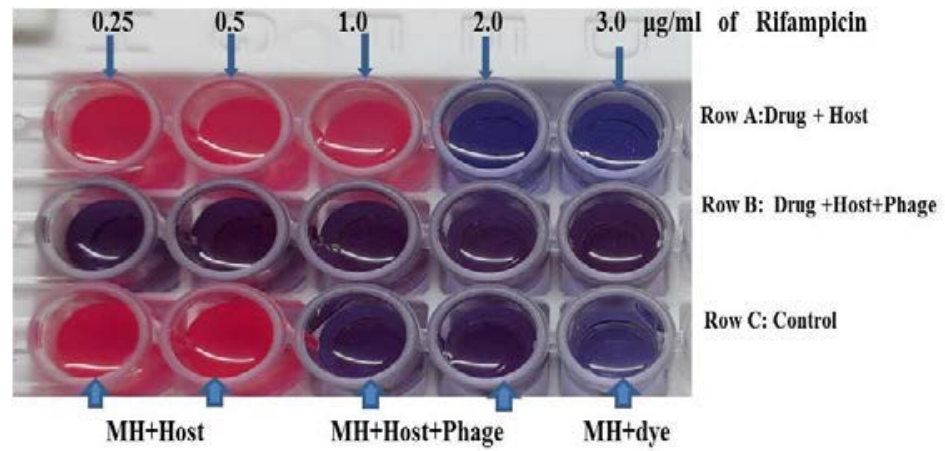

Figure 2: Synergistic action of mycobacteriophage and Rifampicin on Mycobacterium tuberculosis MTCC 300

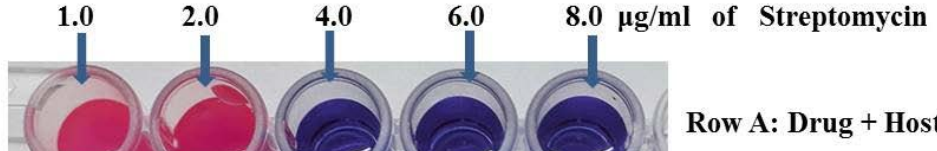

Mycobacterium tuberculosis MTCC 300

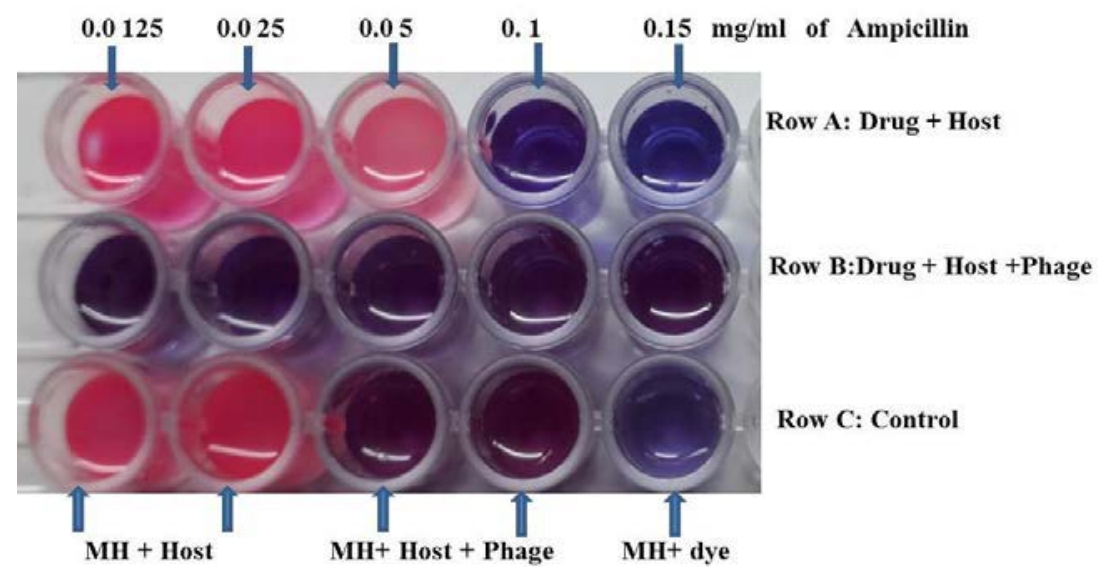

Figure 4: Synergistic action of mycobacteriophage and Ampicillin on Mycobacterium tuberculosis MTCC 300 


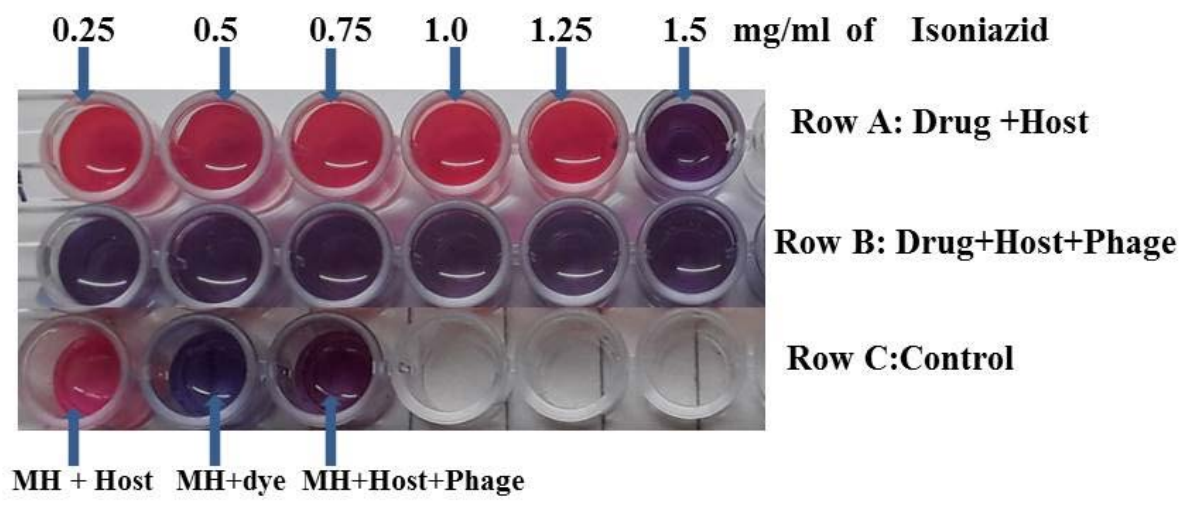

Figure 5: Synergistic action of mycobacteriophage and Isoniazid on Mycobacterium smegmatis MTCC 994

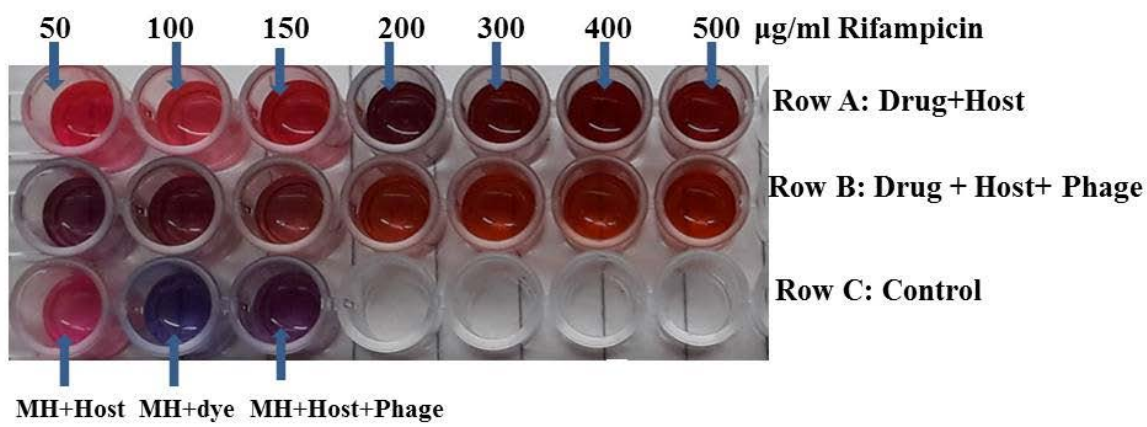

Figure 6: Synergistic action of mycobacteriophage and Rifampicin on Mycobacterium smegmatis MTCC 994

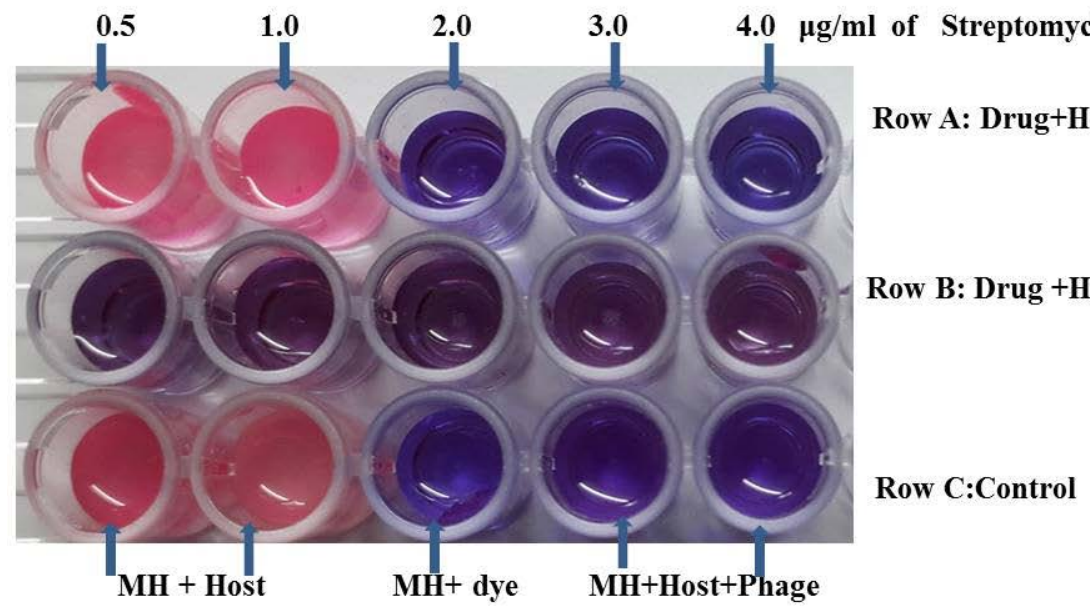

Figure 7: Synergistic action of mycobacteriophage and Streptomycin on Mycobacterium smegmatis MTCC 994 

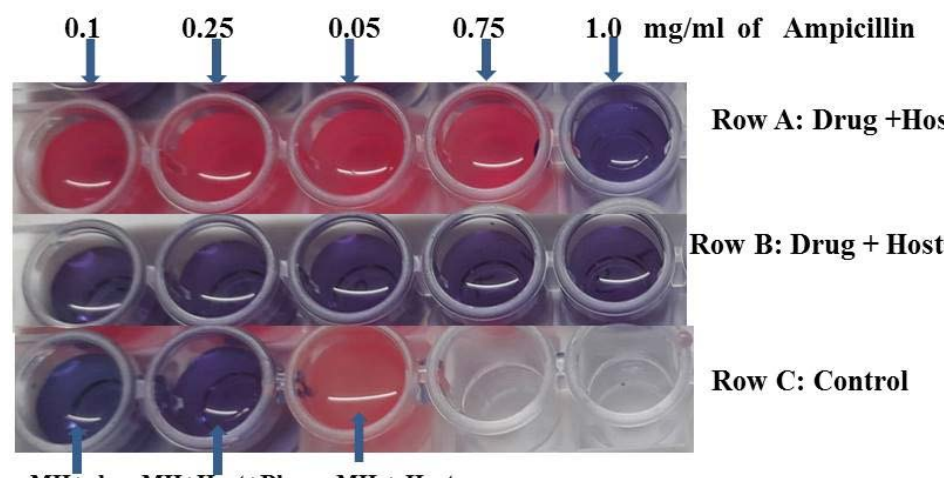

Row A: Drug +Host

Row B: Drug + Host+ Phage

Row C: Control

\section{Figure 8: Synergistic action of mycobacteriophage and Ampicillin on Mycobacterium smegmatis MTCC 994}

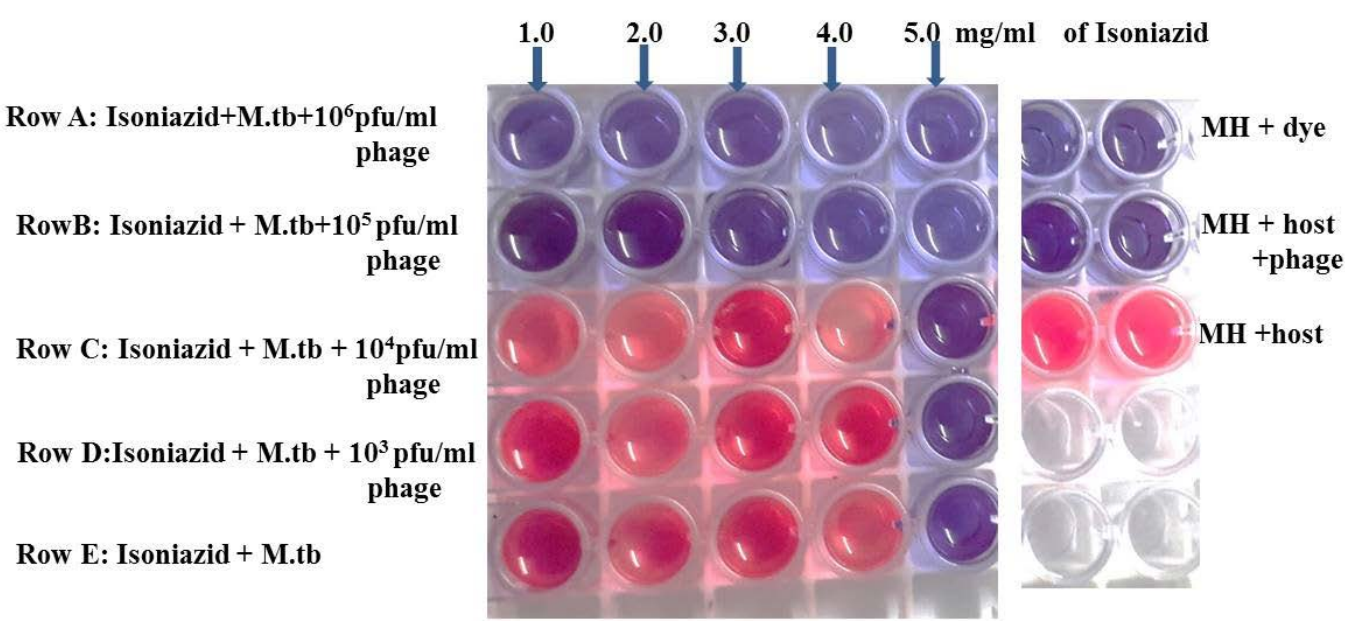

Figure 9: Synergistic action of combinations of mycobacteriophage and Isoniazid on Mycobacterium tuberculosis MTCC 300

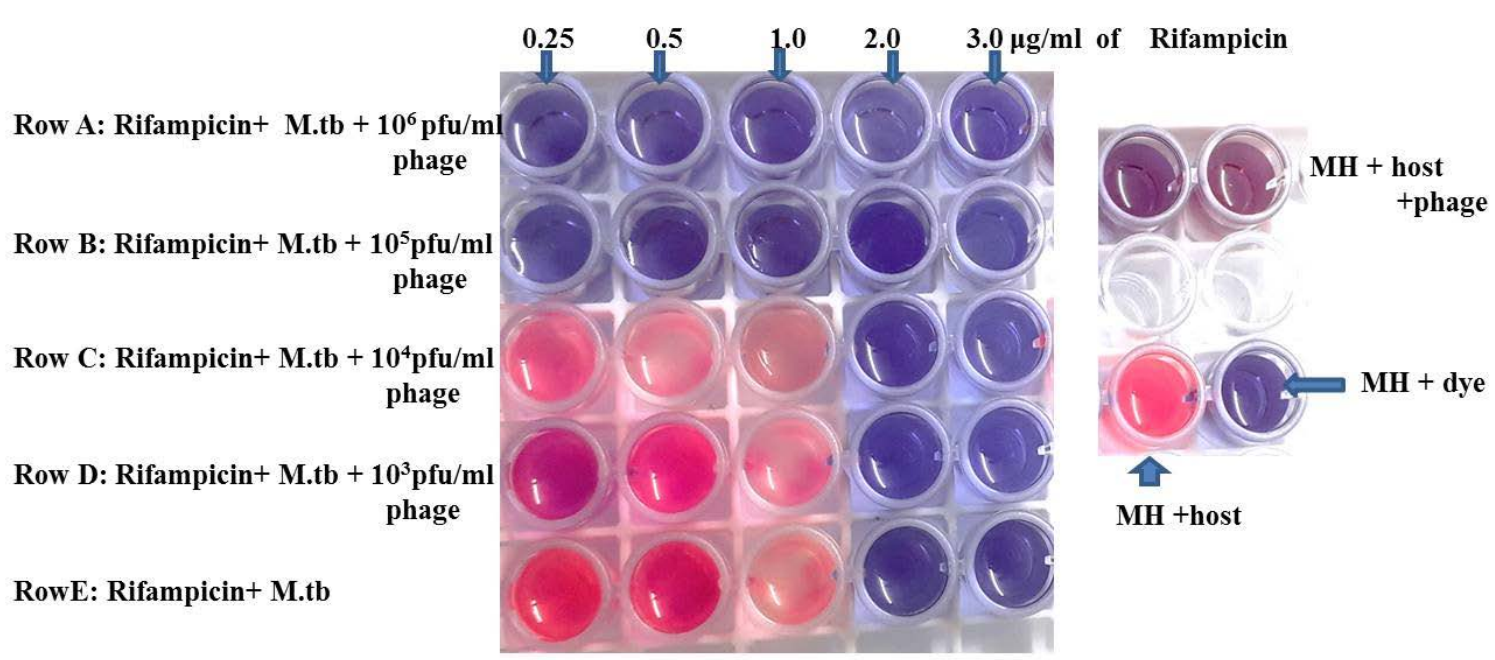

Figure 10: Synergistic action of combinations of mycobacteriophage and Rifampicin on Mycobacterium tuberculosis MTCC 300 


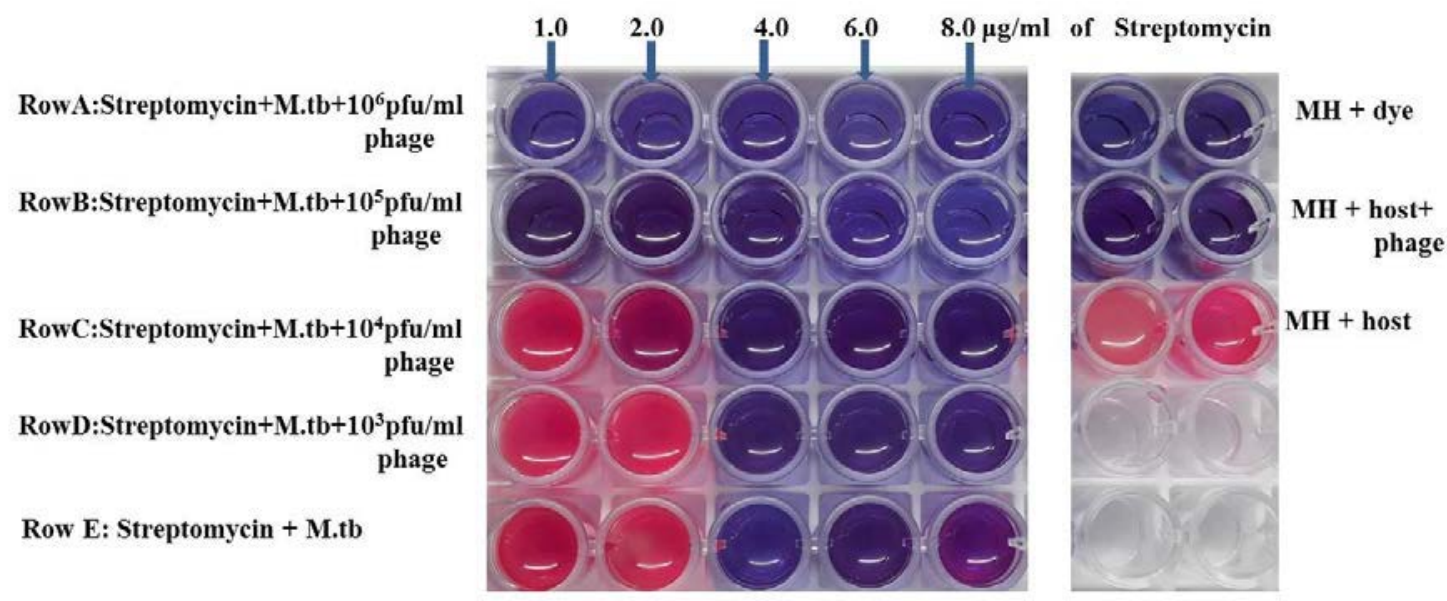

Figure 11: Synergistic action of combinations of mycobacteriophage and Streptomycin on

Mycobacterium tuberculosis MTCC 300

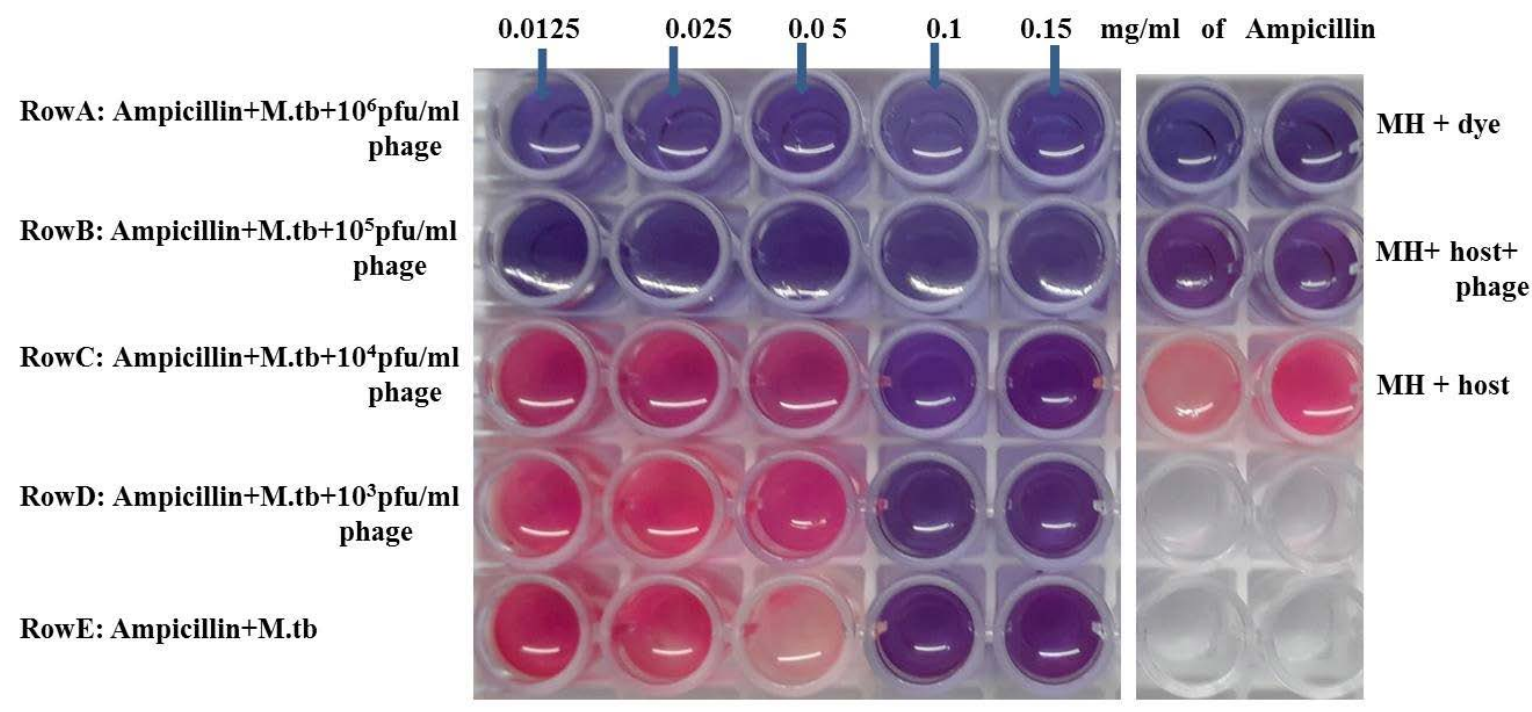

Figure 12: Synergistic action of combinations of mycobacteriophage and Ampicillin on Mycobacterium tuberculosis MTCC 300 


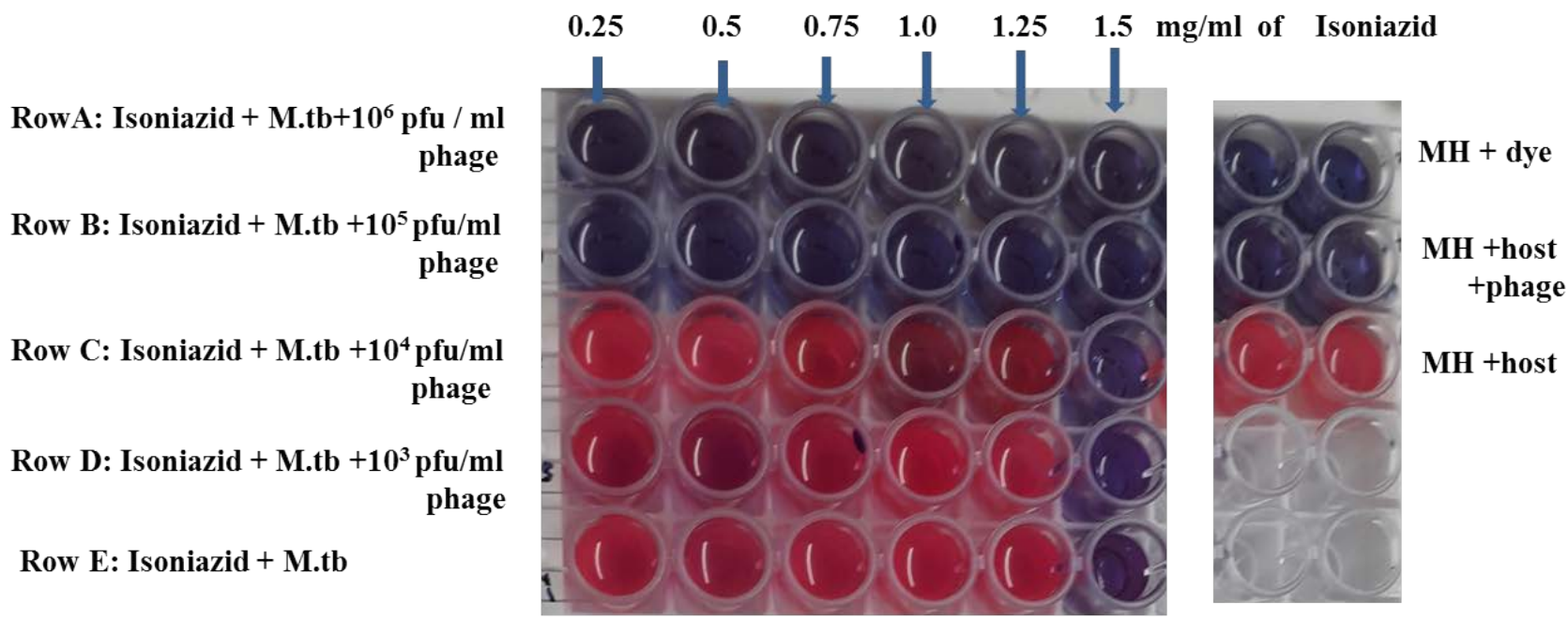

Figure 13: Synergistic action of combinations of mycobacteriophage and Isoniazid on Mycobacterium smegmatics MTCC 994

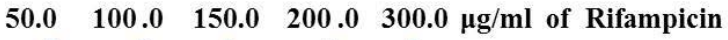

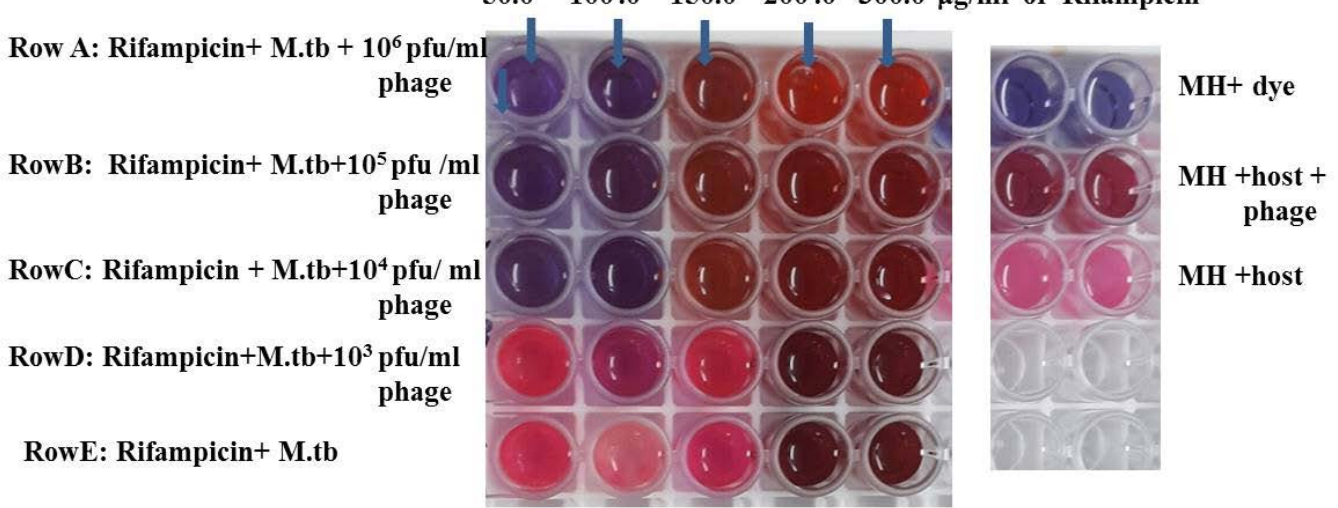

Figure 14: Synergistic action of combinations of mycobacteriophage and Rifampicin on Mycobacterium smegmatics MTCC 994

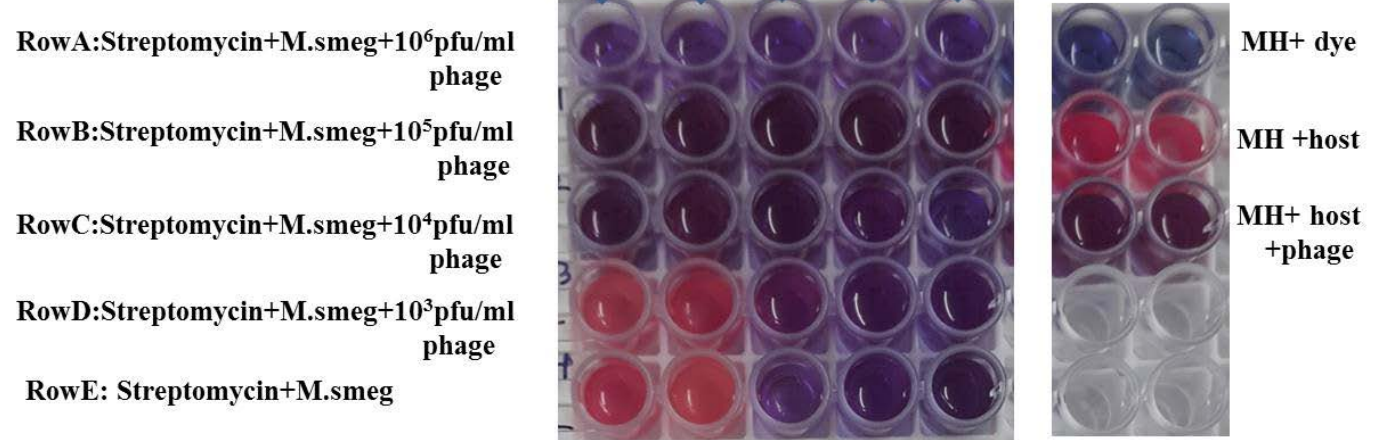

Figure 15: Synergistic action of combinations of mycobacteriophage and Streptomycin on Mycobacterium smegmatics MTCC 994 


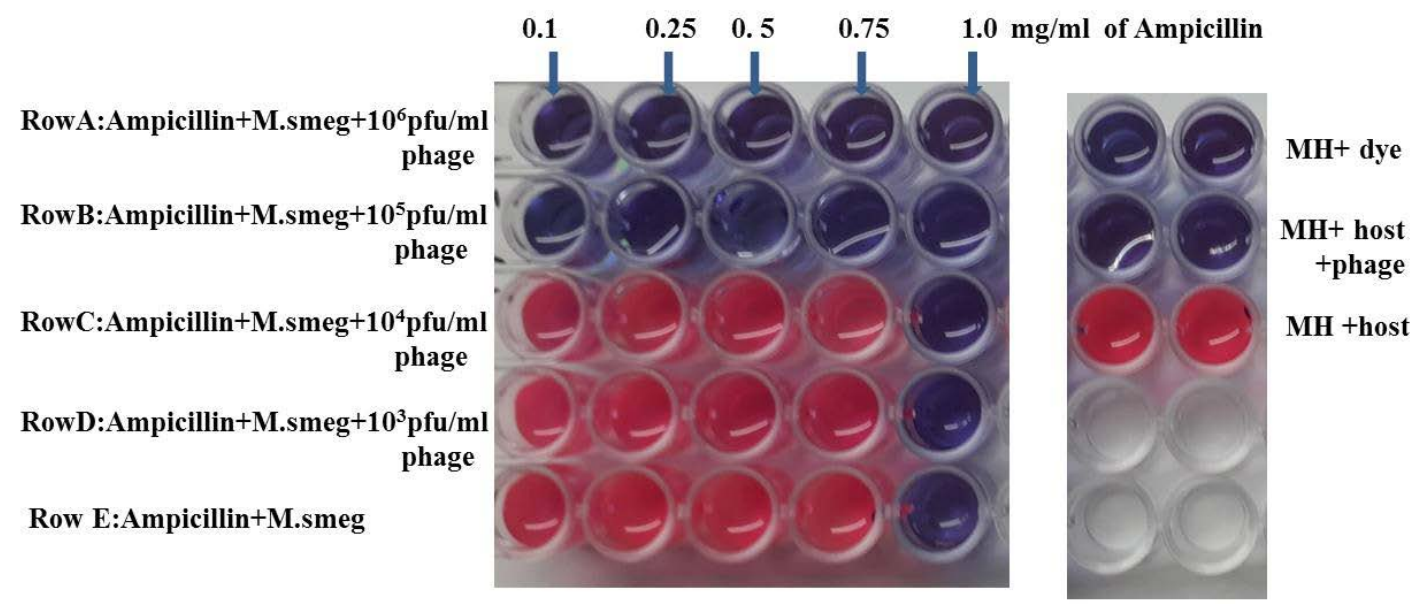

Figure 16: Synergistic action of combinations of mycobacteriophage and Ampicillin on Mycobacterium smegmatics MTCC 994

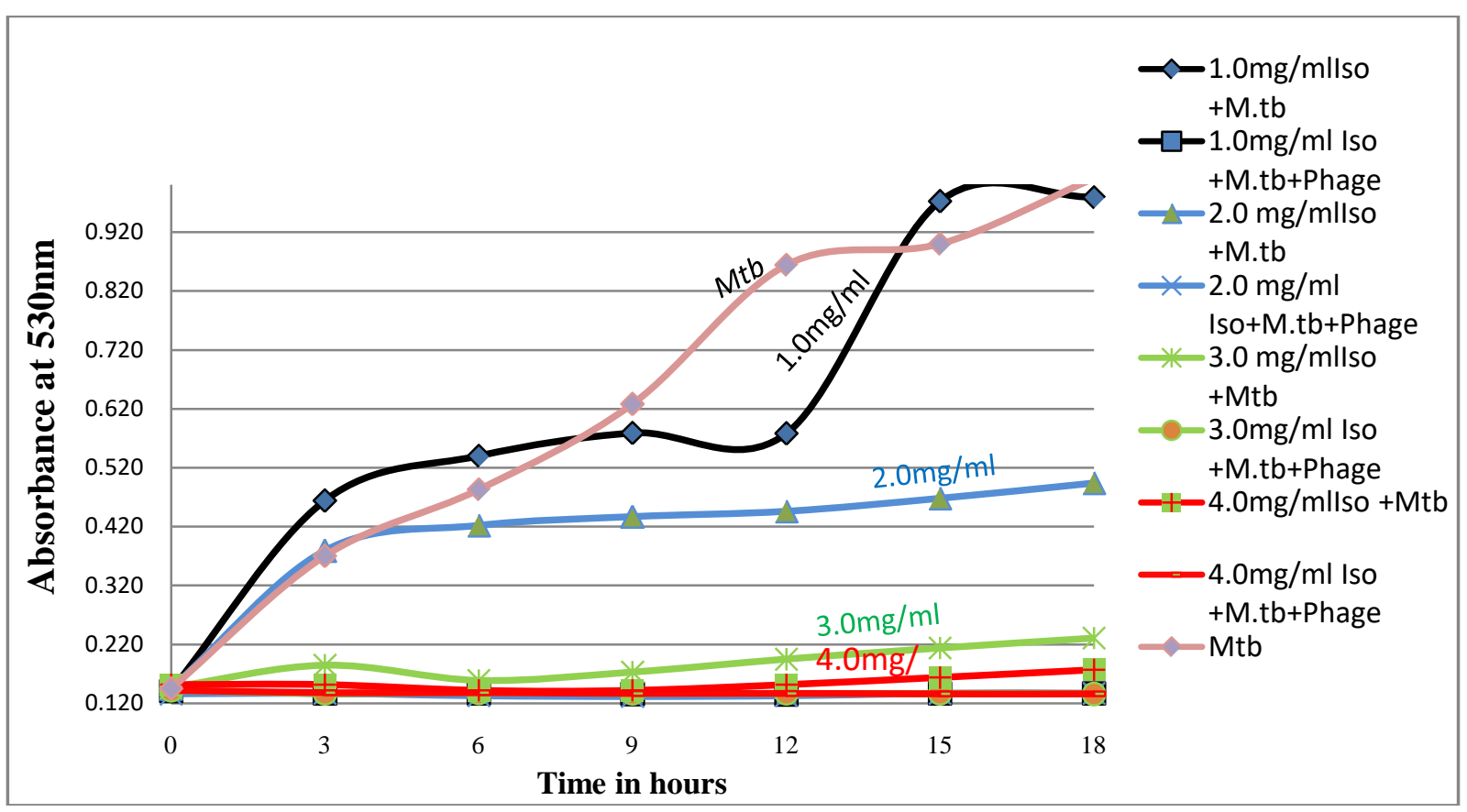

Figure 17: Growth curve of M.tb in presence of phage and Isoniazid 


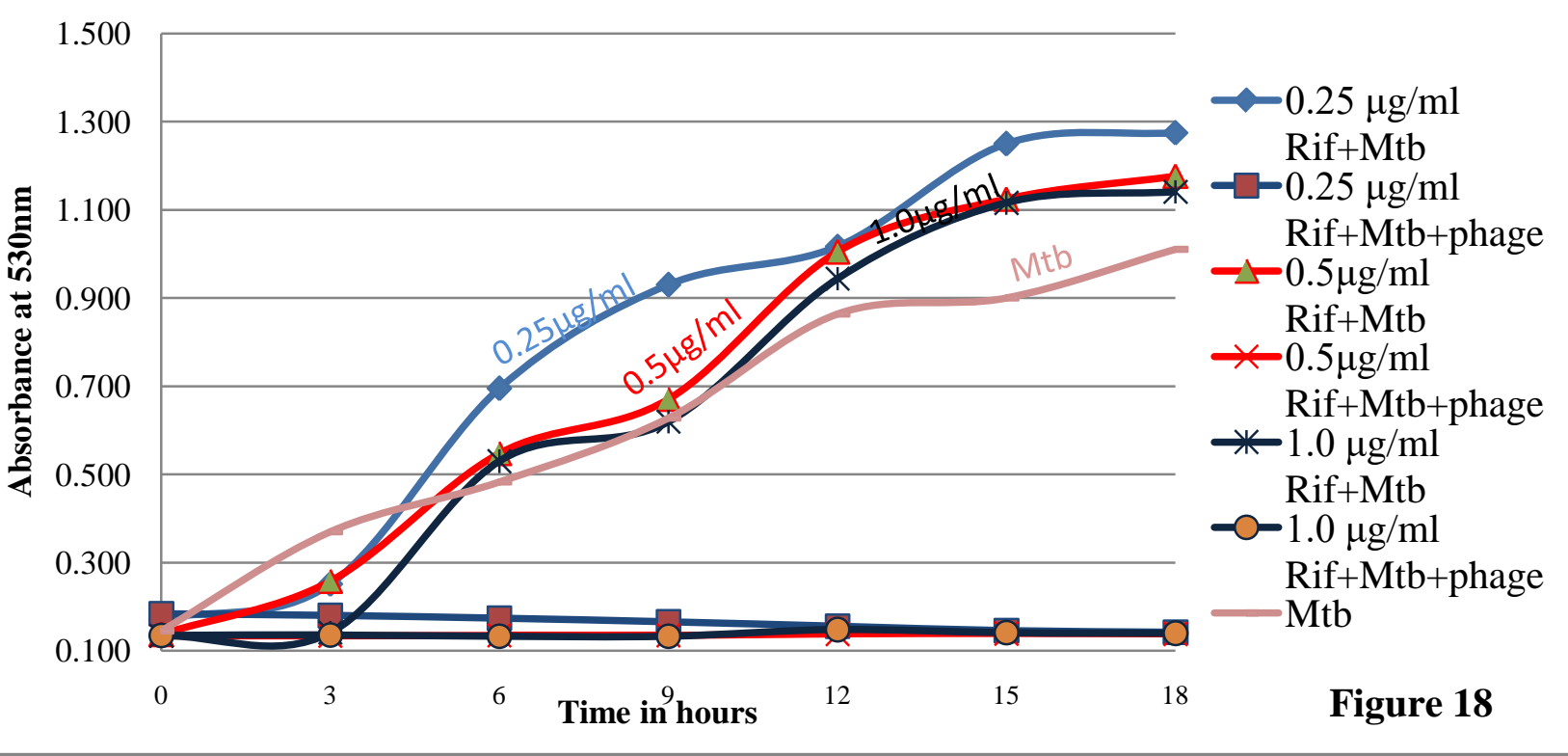

Figure 18: Growth curve of M.tb in presence of phage and Rifampicin

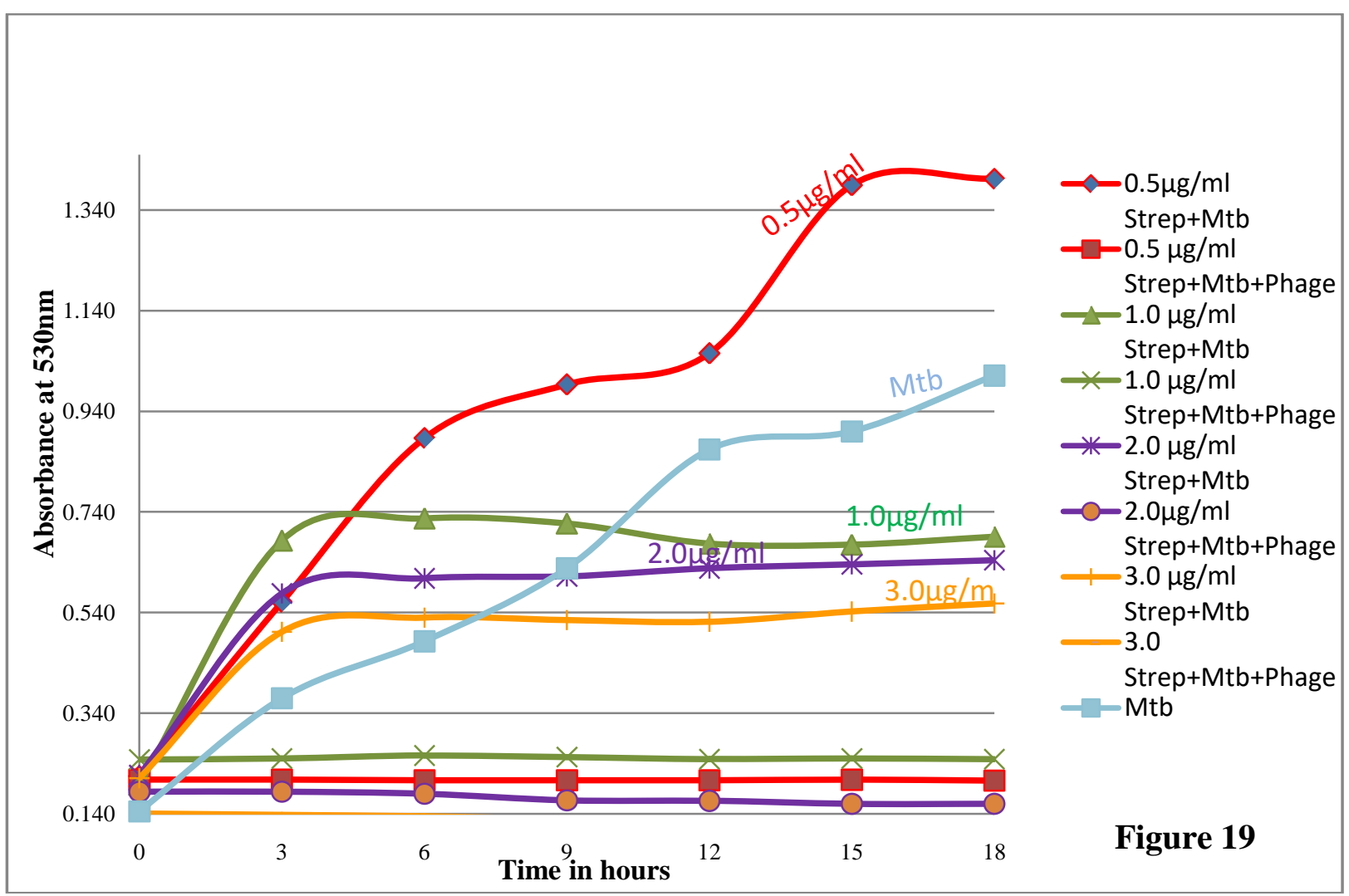

Figure 19: Growth curve of M.tb in the presence of phage and Streptomycin 


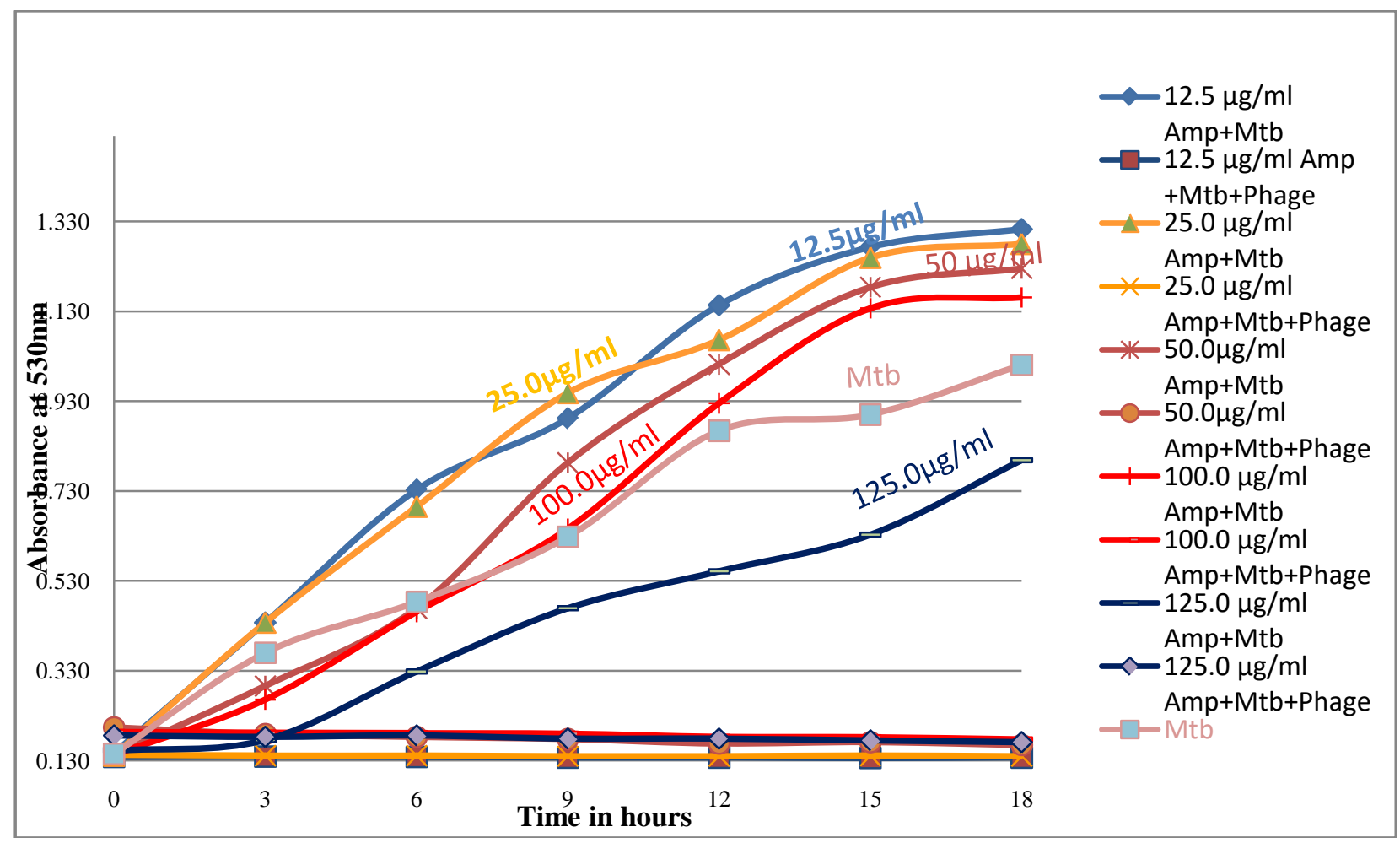

Figure 20: Growth curve of M.tb in the presence of phage and Ampicillin

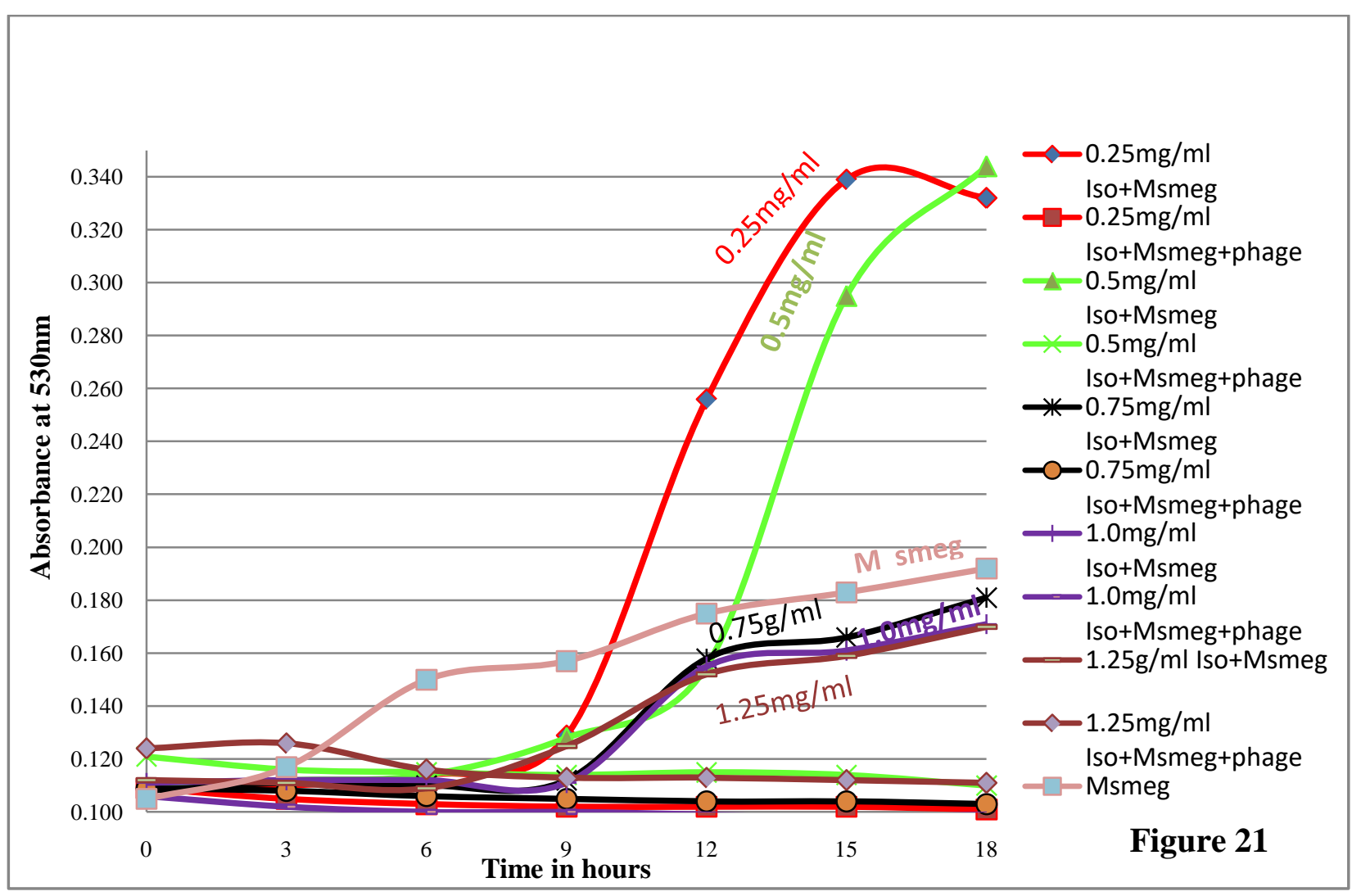

Figure 21: Growth of M.smeg in the presence of phage and Isoniazid 


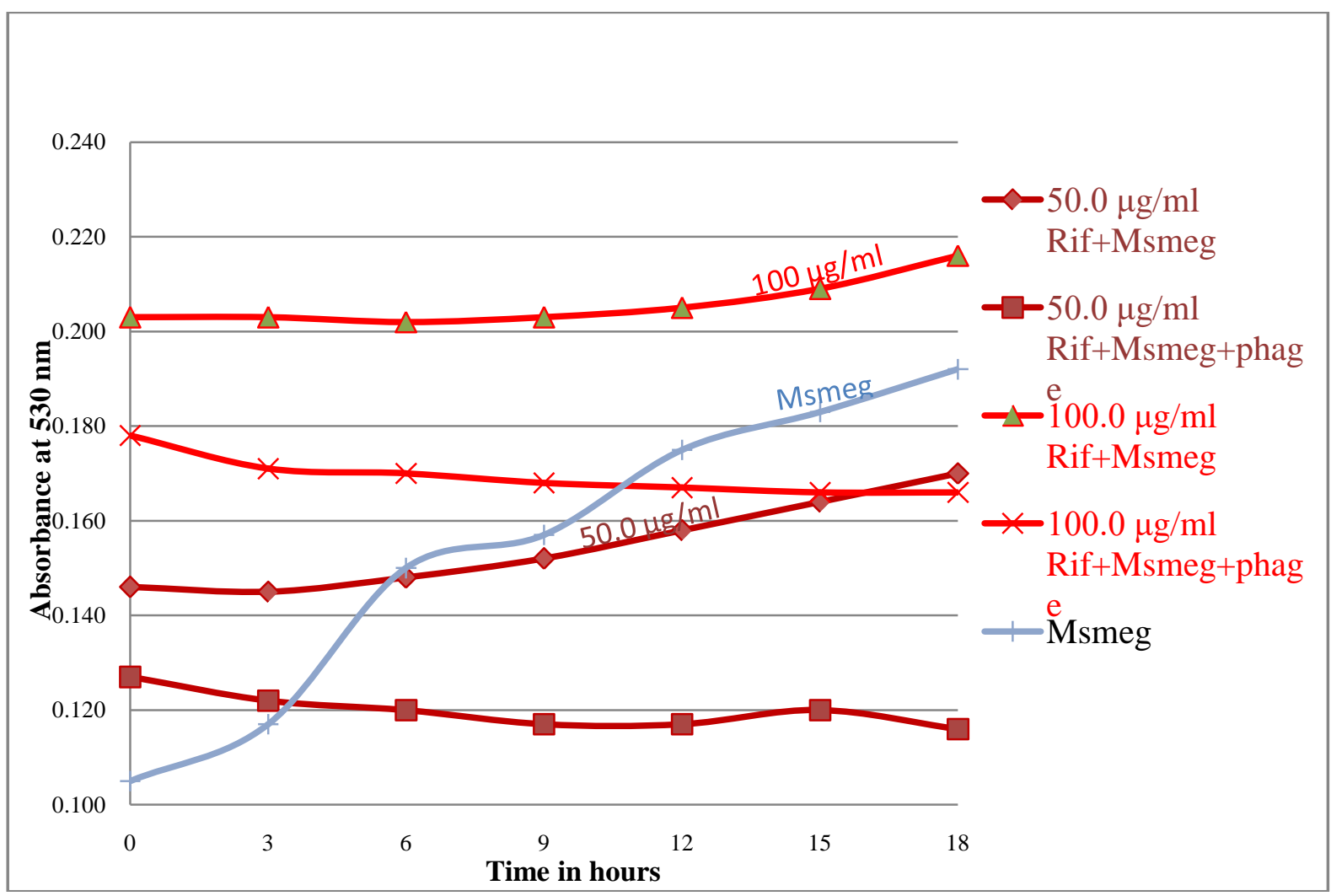

Figure 22: Growth curve of M.smeg in the presence of phage and Rifampicin

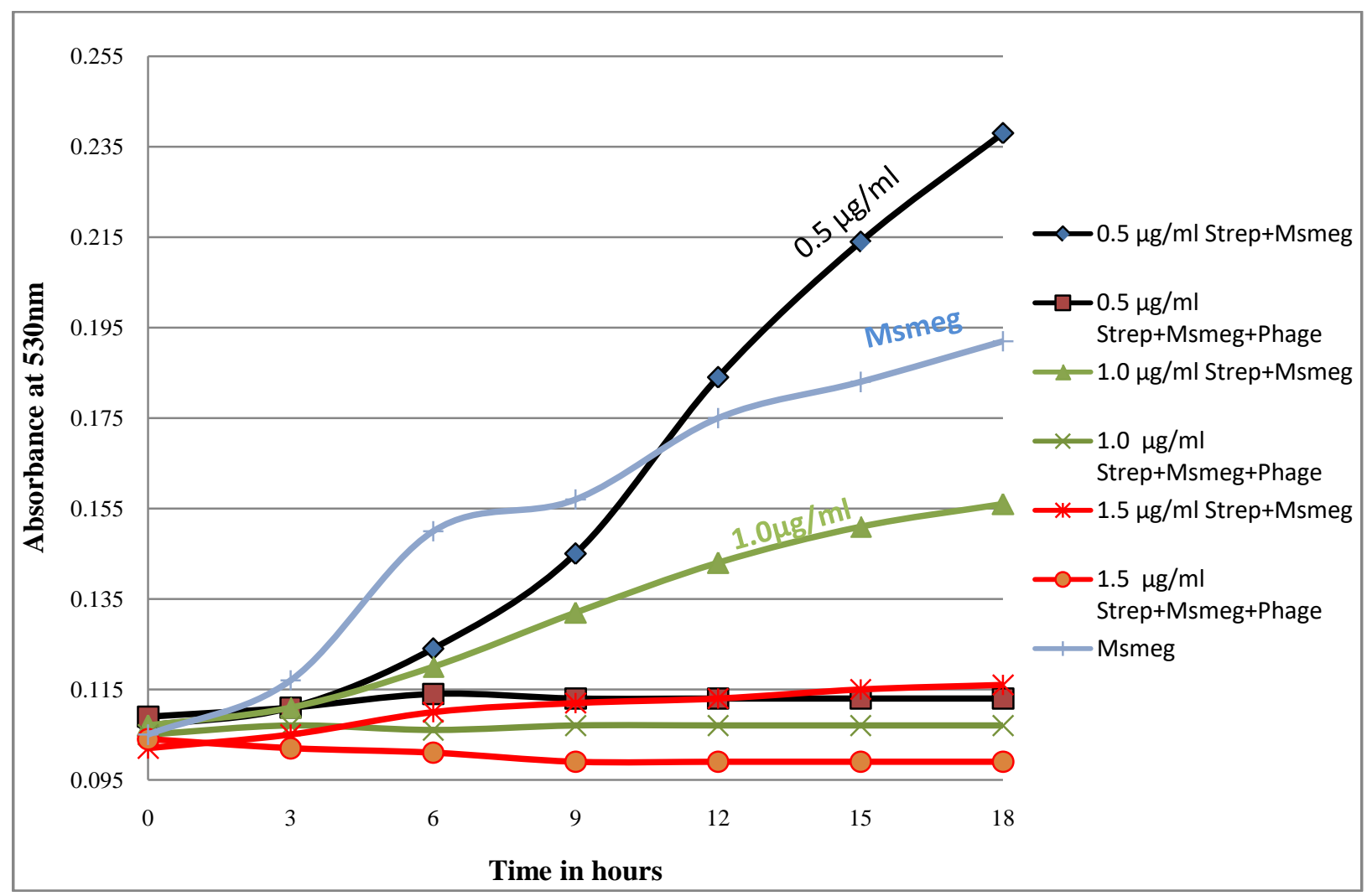

Figure 23: Growth curve of M.smeg in the presence of phage and Streptomycin 


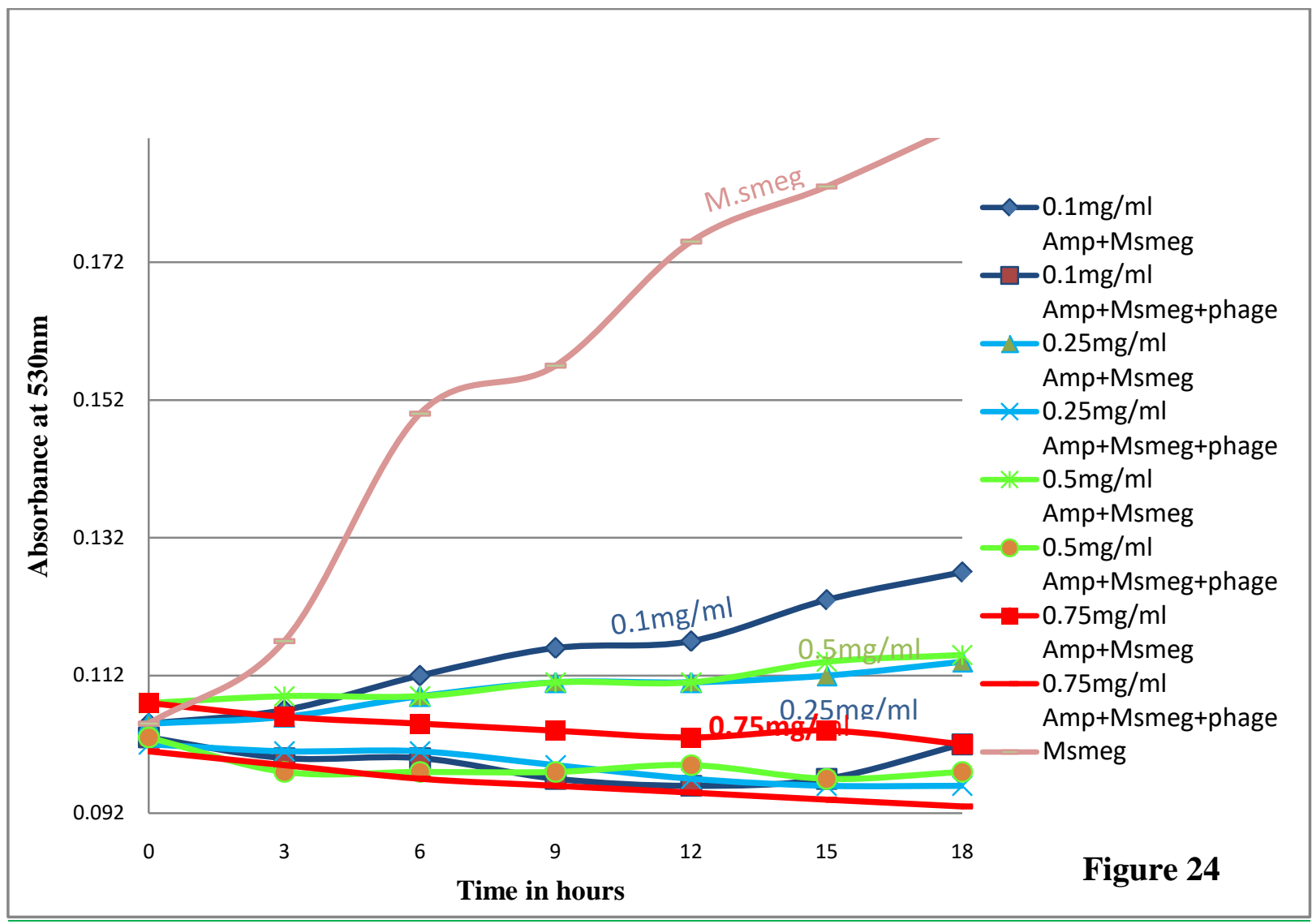

Figure 24: Growth curve of M.smeg in the presence of phage and Ampicillin

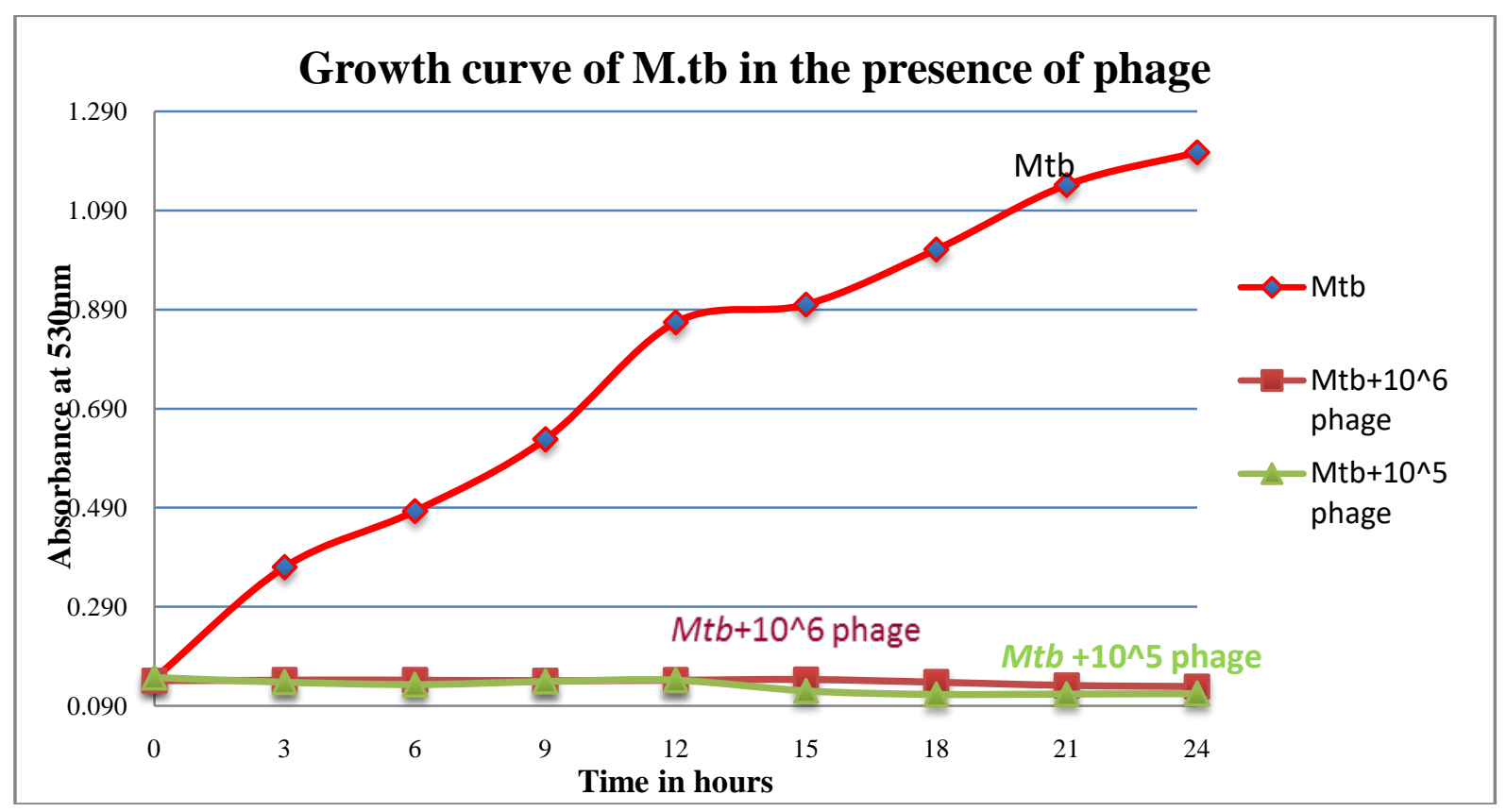

Figure 25: Growth curve of M.tb in the presence of phage 


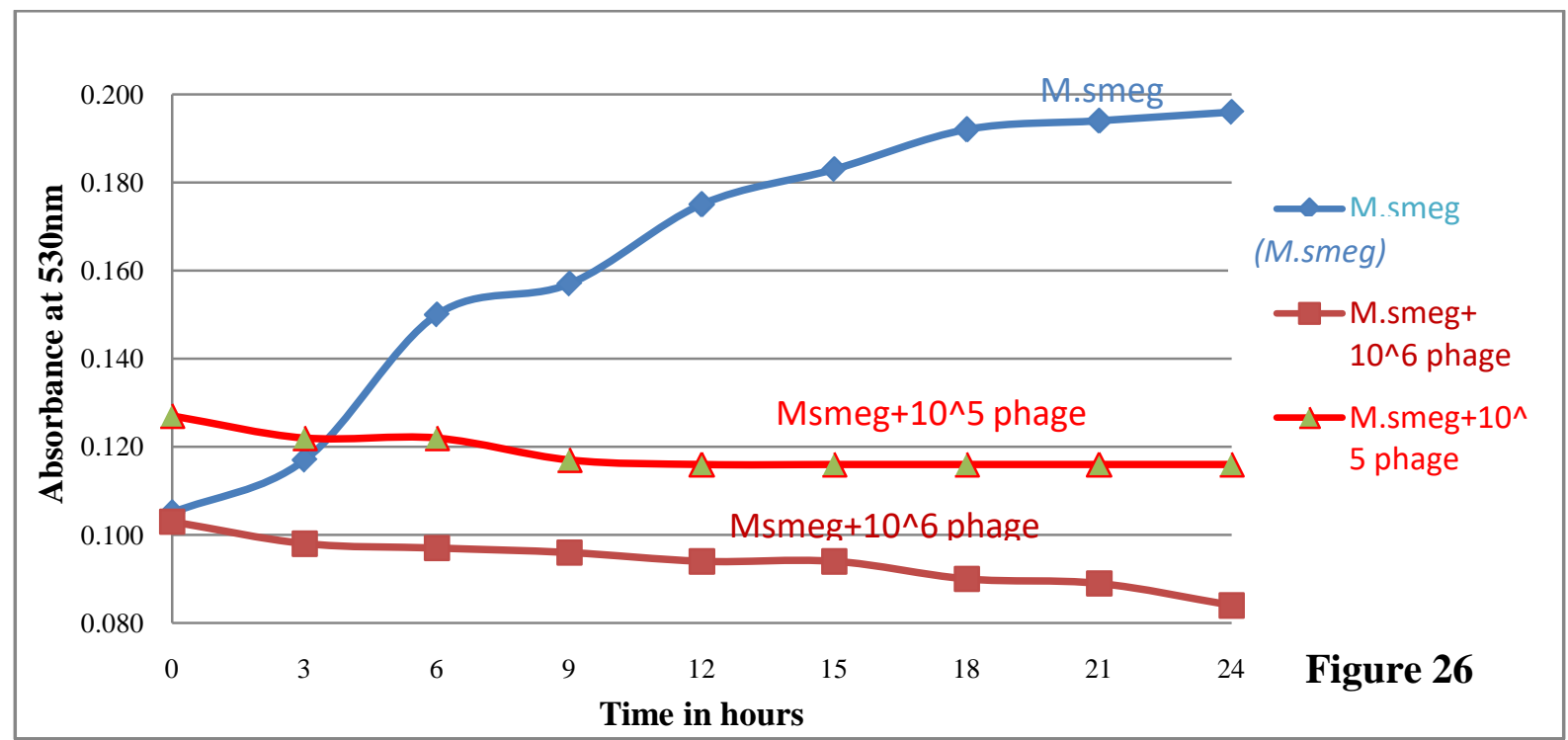

Figure 26: Growth curve of M.smeg in the presence of phage

Website

1. WHO Global tuberculosis report 2018, https://www. who.int/ tb/ publications/global report/en/ (cited on $10^{\text {th }}$ August 2019).

2. Tuberculosis Coalition for Technical Assistance. International standards for tuberculosis care. https://www.who.int/tb/publications/2006/istc_report .pdf (cited on 12 ${ }^{\text {th }}$ August 2019).

3. https://phagesdb.org/hosts/genera/1/ (cited on 4th Septmber 2019).

\section{References Références Referencias}

1. Abedon, S. T., Kuhl, S. J., Blasdel, B. G., and Kutter, E. M. (2011). Phage treatment of human infections. Bacteriophage, 1(2), 66-85. doi: 10.4161/bact.1.2. 15845.

2. Abedon, S.T. and Thomas-Abedon,C. (2010).Phage therapy pharmacology. Curr. Pharm. Biotechnol., 11(1), 28-47.doi:10.2174/138920110790725410.

3. Ahmad,S.(2010). New approaches in the diagnosis and treatment of latent tuberculosis infection. Respir Res., 11(1), 169-185. doi: 10.1186/1465-992111-169.

4. Caminero, J.A., Sotgiu, G., Zumla, A. and Migliori, G. B. (2010). Best drug treatment for multidrugresistant and extensively drug-resistant tuberculosis. Lancet Infect. Dis., 10, 621-629. doi:10.1016/S14733099(10)70139-0.

5. Dedrick, R.M., Guerrero-Bustamante, C.A., Garlena, R.A, Russell, D.A., Ford, K., Harris, K., Gilmour, K.C., Soothill, J., Jacobs-Sera, D., Schooley, R.T., Hatfull, G. F. and Spencer, H.(2019). Engineered bacteriophages for treatment of a patient with a disseminated drug-resistant Mycobacteriuma bscessus. Nat. Med., 25(5), 730-733. doi: 10.1038 /s41591-019-0437-z.
6. Dinnes, J., Deeks, J., Kunst, H., Gibson, A., Cummins, E., Waugh, N., Drobniewski, F. and Lalvani,A. (2007). A systematic review of rapid diagnostic tests for the detection of tuberculosis infection. Health Technol. Assess, 11(3), 1-196.doi: https://www.ncbi.nlm.nih.gov/pubmed/17266837.

7. Gondil, V.S. and Chhibber, S.(2018). Exploring potential of phage therapy for tuberculosis using model organism. Biomed. Biotechnol. Res. J., 2,915.doi: 10.4103/bbrj.bbrj 9317.

8. Guo,S. and Zhi, A. (2012). Phage in the diagnosis and treatment of tuberculosis.Front Biosci., 17, 2691-2697. https://pdfs.semanticscholar.org/8650/ cfbed4589b430d5f52461 dac9829fb58ca83.pdf

9. Hatfull, G. F. (2014). Mycobacteriophages: windows into tuberculosis. PLoSPathogens, 10(3), e1003953 https://doi.org/10.1371/journal.ppat.1003 953.

10. Hatfull, G.F. (2012). The secret lives of mycobacteriophages. Adv. Virus Res., 82, 179288. doi:10.1016/B978-0-12-394621-8.00015-7.

11. Leimane, V., Riekstina, V., Holtz, T.H., Zarovska, E., Skripconoka, V., Thorpe, L.E., Laserson, K.F. and Wells, C.D. (2005). Clinical outcome of individualized treatment of multidrug-resistant tuberculosis in Latvia: a retrospective cohort study. Lancet, 365(9456), 318-326. doi: 10.1016/S0140s6736(05)17786-1.

12. Lin, D. M., Koskella, B., and Lin, H. C. (2017). Phage therapy: An alternative to antibiotics in the age of multidrug-resistance. World J. Gastrointest. Pharmacol. Ther., 8(3), 162-173. doi: 10.4292/ wjgpt.v8.i3.162.

13. Li, P., Yong-ai, L., Bao wen, C., Youlun, L., Xiaobing, S., Cheng, S. and Guozhi, W. (2009). Therapeutic effect of bacteriophage D29 in the treatment for 
guinea pigs infected with sensitive strain of Mycobacterium tuberculosis. Chinese $J$ of Zoonoses, 25 (08), 733-736.

14. Matsuzaki, S., Rashel, M., Uchiyama, J., Sakurai, S., Ujihara, T., Kuroda, M., and Ikeuchi, M. (2005). Bacteriophage therapy: A revitalized therapy against bacterial infectious diseases. J. Infect.Chemother., 11(5), 211-9. doi: 10.1007/s10156-005-0408-9.

15. Merril, C. R., Biswas, B., Carlton, R., Jensen, N. C., Creed, G. J., Zullo, S. and Adhya, S. (1996). Longcirculating bacteriophage as antibacterial agents. Proc. Natl. Acad. Sci., U S A., 93(8), 31883192. doi:10.1073/pnas.93.8.3188

16. Pereira, J. M., David, H. L. and Rastogi, N.(1983). Isolation and partial characterization of temperaturesensitive mutants of the mycobacteriophage D29. Virologie,134,33-49.doi: https://doi.org/10.1016/ S0769-2617(83)80040-9.

17. Pope, W. H., Ferreira, C. M., Jacobs-Sera, D., Benjamin, R. C., Davis, A. J.De Jong, R. J.,et al(2011). Cluster K mycobacteriophages: insights into the evolutionary origins of mycobacteriophage TM4. PloS one, 6(10), e26750. doi:10.1371/journal. pone.0026750.

18. Samaddar, S., Grewal, R. K., Sinha, S., Ghosh, S., Roy, S.and Das Gupta, S. K. (2016). Dynamics of Mycobacteriophage-Mycobacterial Host Interaction: Evidence for Secondary Mechanisms for Host Lethality. Appl. Environ. Microbiol., 82(1), 124-133. doi:10.1128/AEM.02700-15.

19. Satish, R. and Desouza, A.(2019). Study of the characteristics of mycobacteriophage - A novel tool to treat Mycobacterium spp. Int. J.Mycobacteriol., 8(2), 170-174. doi:10.4103/ijmy.ijmy_42_19

20. Satish, R. and Desouza, A.(2018). Isolation of mycobacteriophage: Novel tool to treat Mycobacterium spp. Int. J. Sci. Res. Biol. Sci., 5, 46-50. doi: https://doi.org/10.26438/ijsrbs/v5i2.4650

21. Shah, N. S., Wright, A., Bai, G. H., Barrera, L., Boulahbal, F., Martín-Casabona, N. ,Cegielski, J. P. et al (2007). Worldwide emergence of extensively drugresistanttuberculosis. Emerg Infect Dis, 13(3), 380-387. doi:10.3201/eid1303.061400.

22. Sulakvelidze, A., Alavidze, Z. and Morris, J.G. Jr. (2001). Bacteriophage Therapy. Antimicrob. Agents Chemother., 45(3), 649- 659. doi: 10.1128/AAC.45. 3.649-659.2001

23. Tanji, Y. (2005). Therapeutic use of phage cocktail for controlling Escherichia coli O157:H7 in gastrointestinal tract of mice. J.Biosci.Bioeng., 100 (3), 280-287.doi: 10.1263/jbb.100.280.

24. Tanji, Y.(2004). Toward rational control of Escherichia coli O157: H7 by a phage cocktail. Appl. Microbiol. Biotechnol., 64 (2), 270-4.doi: 10.1007/s 00253-003-1438-9.

25. Vitiello, C.L., Merril, C.R. and Adhya,S. (2005). An amino acid substitution in a capsid protein enhances phage survival in mouse circulatory system more than a 1000- fold. Virus Res., 114 (1-2),101-103. doi:10.1016/j.virusres.2005.05.014. 
